\title{
A novel therapeutic approach with Caviunin-based isoflavonoid that en routes bone marrow cells to bone formation via BMP2/Wnt- $\beta$-catenin signaling
}

\author{
P Kushwaha ${ }^{1}$, V Khedgikar ${ }^{1}$, J Gautam ${ }^{1}$, P Dixit' ${ }^{2}$, R Chillara ${ }^{2}$, A Verma ${ }^{3}$, R Thakur ${ }^{1}$, DP Mishra ${ }^{1}$, D Singh ${ }^{1}$, R Maurya ${ }^{2}$, \\ N Chattopadhyay ${ }^{1}$, PR Mishra ${ }^{3}$ and R Trivedi ${ }^{*}, 1$
}

Recently, we reported that extract of Dalbergia sissoo made from leaves and pods have antiresorptive and bone-forming effects. The positive skeletal effect attributed because of active molecules present in the extract of Dalbergia sissoo. Caviunin 7-0-[ $\beta$-Dapiofuranosyl-(1-6)- $\beta$-D-glucopyranoside] (CAFG), a novel isoflavonoid show higher percentage present in the extract. Here, we show the osteogenic potential of CAFG as an alternative for anabolic therapy for the treatment of osteoporosis by stimulating bone morphogenetic protein 2 (BMP2) and Wnt/ $\beta$-catenin mechanism. CAFG supplementation improved trabecular microarchitecture of the long bones, increased biomechanical strength parameters of the vertebra and femur and decreased bone turnover markers better than genistein. Oral administration of CAFG to osteopenic ovariectomized mice increased osteoprogenitor cells in the bone marrow and increased the expression of osteogenic genes in femur and show new bone formation without uterine hyperplasia. CAFG increased mRNA expression of osteoprotegerin in bone and inhibited osteoclast activation by inhibiting the expression of skeletal osteoclastogenic genes. CAFG is also an effective accelerant for chondrogenesis and has stimulatory effect on the repair of cortical bone after drill-hole injury at the tissue, cell and gene level in mouse femur. At cellular levels, CAFG stimulated osteoblast proliferation, survival and differentiation. Signal transduction inhibitors in osteoblast demonstrated involvement of p-38 mitogen-activated protein kinase pathway stimulated by BMP2 to initiate Wnt/ $\beta$-catenin signaling to reduce phosphorylation of GSK3- $\beta$ and subsequent nuclear accumulation of $\beta$-catenin. Osteogenic effects were abrogated by Dkk1, Wnt-receptor blocker and FH535, inhibitor of TCF-complex by reduction in $\beta$-catenin levels. CAFG modulated MSC responsiveness to BMP2, which promoted osteoblast differentiation via Wnt/ $\beta$-catenin mechanism. CAFG at $1 \mathrm{mg} / \mathrm{kg}^{\prime}$ day dose in ovariectomy mice (human dose $\sim 0.081 \mathrm{mg} / \mathrm{kg}$ ) led to enhanced bone formation, reduced bone resorption and bone turnover better than well-known phytoestrogen genistein. Owing to CAFG's inherent properties for bone, it could be positioned as a potential drug, food supplement, for postmenopausal osteoporosis and fracture repair.

Cell Death and Disease (2014) 5, e1422; doi:10.1038/cddis.2014.350; published online 18 September 2014

Osteoporosis has been called as a silent epidemic, characterized by reduced bone mineral density (BMD) and deterioration of bone micro-architecture that leads to enhanced bone fragility and increased risk of fracture. ${ }^{1}$ The problem of this disease in India is even more alarming as 61 million people suffer from this disease. Therefore, formation of bone is the ultimate strategy that one aims for the treatment of disease like osteoporosis. ${ }^{1}$ The major cause of post-menopausal osteoporosis is deficiency of female steroid hormone estrogen. Both men and women start losing bones after the age of 40 years but the rate of loss is faster in women due to menopause. Subsequently, the incidence of bone fractures is two- to threefold high in women as compared with men. ${ }^{2}$

FDA-approved drugs for osteoporosis fall into two categories: the anabolic. which induce osteoblast formation such as parathyroid hormone (PTH) ${ }^{3}$ and anti-resorptive drugs, which inhibit osteoclast function such as bisphosphonates, estrogen and estrogen analogs. ${ }^{4,5}$ PTH (teriparatide) has exhibited promising results with doubled the rate of bone formation, reduced (60-70\%) vertebral fracture and reduction

\footnotetext{
${ }^{1}$ Division of Endocrinology, Center for Research in Anabolic Skeletal Targets in Health and IIIness (ASTHI), CSIR-Central Drug Research Institute, Lucknow 226031, India; ${ }^{2}$ Medicinal and Process Chemistry Division, Central Drug Research Institute, CSIR-CDRI, Lucknow 226031, India and ${ }^{3}$ India Division of Pharmaceutics, Central Drug Research Institute, CSIR-CDRI, Lucknow 226031, India

${ }^{*}$ Corresponding author: R Trivedi, Division of Endocrinology, Center for Research in Anabolic Skeletal Targets in Health and IIIness (ASTHI), CSIR Central Drug Research Institute, Sector 10, Jankipuram Extension, Sitapur Road, Lucknow 226031, India. Tel: + 91 9415769219; Fax: + 91522 2771941; E-mail: ritu_trivedi@cdri.res.in or ritu_pgi@yahoo.com

Abbreviations: CAFG, caviunin 7-O-[ $\beta$-D-apiofuranosyl-(1-6)- $\beta$-D-glucopyranoside]; ALP, alkaline phosphatase activity; BFR, bone formation rate; MAR, mineral apposition rate; BrdU, 5-bromo-2'-deoxyuridine; BMC, bone marrow cell; ALN, alendronate; BMP2, bone morphogenetic protein 2; BV/TV, bone volume/tissue volume; Tb.No, trabecular number; Tb.Th, trabecular thickness; SMI, structural model index; COL1, collagen type 1; $\alpha$-MEM, $\alpha$-minimum essential medium eagle; $\mu$-CT, microcomputed tomography; PTH, parathyroid hormone; OCN, osteocalcin; OPG, osteoprotegrin; Runx2, Runt-related transcription factor 2; RANKL, receptor activator of nuclear factor kappa-B ligand; RANK, receptor activator of nuclear factor kappa-B; OVx, ovariectomy; Q-PCR, quantitative real-time PCR; TRAP, tartarate resistant acid phosphatase; BMD, bone mineral density; MAPK, mitogen-activated protein kinase; MTT, 3-(4, 5-dimethylthiazol-2-yl)-2, 5-diphenyltetrazolium bromide

Received 22.4.14; revised 19.6.14; accepted 26.6.14; Edited by C Munoz-Pinedo
} 
in the risk of non-vertebral fractures by about $\sim 50 \%$. However, PTH has shown black box warning of osteosarcoma in small animals. ${ }^{6}$ For anti-resorptive raloxifene, the only SERMs are currently approved for osteoporosis that reduces spine fractures. ${ }^{7}$ It also reduces the risk of hormone-positive breast cancer, ${ }^{8}$ but its effect on cardiovascular disease remains uncertain. ${ }^{9}$ Alendronate (ALN) increased the formation of fibroblastic colonies in cultures of rat bone marrow. ${ }^{10}$ Combination therapy of PTH with ALN have shown synergistic effect on BMD, which is not fully supported by some observational studies. ${ }^{11,12}$ With available literature, further investigation is needed on the long-term risks, benefits of these drugs and development of novel therapies.

The aim of this study was to investigate alternative anabolic drugs for the treatment of osteoporosis. We have identified a novel isoflavone glucoside, caviunin 7-O-[ $\beta$-D-apiofuranosyl-(1-6)- $\beta$-D-glucopyranoside] that has been abbreviated as CAFG, which is extracted from leaves of Dalbergia sissoo Roxb. ${ }^{13}$ It belongs to the legume family (Fabaceae). ${ }^{14}$ Here we show that this potent flavonoid could act like a bioactive molecule and could counteract the deleterious effects of estrogen deficiency occurring during menopause in women. CAFG's potential to induce osteogenesis was measured biochemically by assessing the activity of alkaline phosphatase (ALP) and then mineralization. ${ }^{13}$ Overall, data show that CAFG, a novel isoflavonoid, enhanced osteogenic activity more and at much lower doses as compared with its structural analog genistein. Interestingly, CAFG is not estrogenic, instead promoted osteoblastic differentiation by activating the bone morphogenetic protein 2 (BMP2)-Wnt/ $\beta$-catenin signaling pathway. We also show that CAFG modulates the cortical bone repair process after drill-hole injury by enhancing the function and differentiation of osteoblast.

\section{Results}

Dose determination of CAFG. Figure 1a shows the structural differences between CAFG $(M W=668)$, caviunin $(\mathrm{MW}=374.34)$ and genistein $(\mathrm{MW}=270.2)$. Basic skeleton of the molecules is the glycine isoflavone; however, CAFG additionally contains two sugar moieties attached to it. $^{13}$ Dose validation by subcutaneously injecting CAFG at doses of $0.5,1.0,5.0$ and $10 \mathrm{mg} / \mathrm{kg}$ body weight for 3 consecutive days shows increased expression for osteogenic genes (ALP, Runt-related transcription factor 2 (Runx2) and collagen type 1 (COL1), Figure $1 \mathrm{~b}$ ) at both 1.0 and $5.0 \mathrm{mg} / \mathrm{kg}$ dose with no stimulation at either low dose of $0.5 \mathrm{mg} / \mathrm{kg}$ or highest dose of $10 \mathrm{mg} / \mathrm{kg}$. Therefore, further experiments were carried out at doses of 1 and $5 \mathrm{mg} / \mathrm{kg}$ of CAFG.
CAFG prevents bone loss in estrogen deficiency model and improves biomechanical strength. Oral administration of CAFG shows its appearance in blood after $3.0 \pm 0.5 \mathrm{~h}$ with a maximum concentration (Cmax) of $160.23 \mathrm{ng} / \mathrm{ml}$. The drug showed AUC value of $1528.91 \pm 107 \mathrm{ngxh} / \mathrm{ml}$ showing rapid absorption (data not shown).

Data of isolated bones by three-dimensional (3D)- $\mu \mathrm{CT}$ show that 6 weeks of ovariectomy (OVx; estrogen withdrawal) induced deterioration of the trabecular micro-architecture owing to destruction of the trabecular bone in the tibia proximal region (Figure 1d), femur epiphysis and Lumber-5 (L-5) vertebrae (Supplementary Data). Treatment with CAFG and GEN at 1 and $5 \mathrm{mg} / \mathrm{kg}$ dose exhibited well-developed trabeculae, comparable to the control Sham + vehicle and standards PTH, ALN. Quantification of these data at the tibial proximal sites shows significantly increased bone volume/ tissue volume (BV/TV; Figure 1e), trabecular thickness (Tb.Th; Figure 1f), trabecular number (Tb.No; Figure 1g) and decreased trabecular separation (Tb.Sp.; Figure 1h) and structural model index (SMI; Figure 1i), as compared with OVx + vehicle group that had significantly reduced $(-80 \%)$ BV/TV, Tb.No, Tb.Th and increased Tb.Sp. and SMI. Interdose comparisons show that $1 \mathrm{mg} / \mathrm{kg}$ dose was more effective in increasing BV/TV $(P<0.05)$ as compared with the $5 \mathrm{mg} / \mathrm{kg}$ dose. Overall, data suggest that $1 \mathrm{mg} / \mathrm{kg}$ oral dose of CAFG and $5 \mathrm{mg} / \mathrm{kg}$ of GEN for 6 weeks treatment were effective enough for more robust changes as compared with other doses of CAFG or GEN. CAFG could not surpass the positive effects as achieved by either PTH or ALN on bone but it showed comparable response.

Biomechanical strength data showed that CAFG dose dependently, especially $1 \mathrm{mg} / \mathrm{kg}$ dose in femur mid-diaphysis region, that is, cortical region of bone, increased femur breaking strength and energy versus the OVx group $(P<0.001, P<0.01)$ (Table 1$)$ and increased L-5 stiffness and energy when compared with all other groups that were comparable to PTH and ALN (Table 1).

CAFG induced new bone formation in mice. Parameters of new bone formation, mineral apposition rate (MAR) ${ }^{15}$ and bone formation rate $(B F R)^{15}$ over unit bone surface area (BFR/BS) were reduced to $\sim 65 \%$ in OVx mice compared with the Sham group $(P<0.001)$ as in Table 1. CAFG, GEN and PTH treatment for 6 weeks increased BFR/BS in OVx mice (Figure 1j). Inter-dose comparisons within group shows that $1 \mathrm{mg}$ dose of CAFG increased bone formation to $\sim 65 \%$ more versus the OVx group and $\sim 13 \%$ more than CAFG (5 mg dose). As compared with $1 \mathrm{mg} / \mathrm{kg}$ dose of GEN, double the amount of BFR/BS was achieved with CAFG at $1 \mathrm{mg} / \mathrm{kg}$ (Table 1).

Figure 1 CAFG has osteogenic but anti-estrogenic effect. (a) Structure of CAFG, caviunin and genistein (GEN). (b) In vivo dose determination of CAFG. CAFG stimulates osteoblastic gene expression at $1 \mathrm{mg} / \mathrm{kg} /$ day and $5 \mathrm{mg} / \mathrm{kg} /$ day doses. Values represent mean $\pm S$.E. ${ }^{\star} P<0.05$ and ${ }^{* \star *} P<0.001$ as compared with the control vehicle group. (c) Representation of 6 weeks treatment protocol with CAFG and standard controls. (d) 3D $\mu$-CT images of trabecular micro-architecture of proximal tibial bone. (e-i) Analysis of trabecular micro-architecture of proximal tibia bone includes parameters BV/TV, Tb.Th, Tb.No, Tb.Sp. and SMl, respectively. All values are expressed as mean \pm S.E. ${ }^{\star} P<0.05,{ }^{* *} P<0.01,{ }^{* \star *} P<0.001$ versus $\mathrm{OVx}$, ${ }^{\#} P<0.05,{ }^{\# \#} P<0.01,{ }^{\# \# \#} P<0.001$ versus GEN $1 \mathrm{mg} / \mathrm{kg} /$ day, ${ }^{*} P<0.05,{ }^{,} P<0.01$ versus CAFG $5 \mathrm{mg} / \mathrm{kg} / \mathrm{day}$ and ${ }^{\mathrm{b}} P<0.01$ versus GEN $5 \mathrm{mg} / \mathrm{kg} /$ day. (j) Transverse sections of tetracycline- and calcein-labeled tibia diaphysis from mice. Six weeks of treatment with CAFG significantly enhanced bone formation. (k) Serum OCN levels as measured at the end of experiment from various treatment groups. Data show that CAFG inhibits bone turnover in OVx mice. Values represent mean \pm S.E. ${ }^{* \star} P<0.001$ versus $\mathrm{OVx}$ and ${ }^{\#} P<0.05$ versus GEN $1 \mathrm{mg} / \mathrm{kg} /$ day. (I) Uterine histology after treatment with CAFG, GEN, PTH and ALN from mice 
a
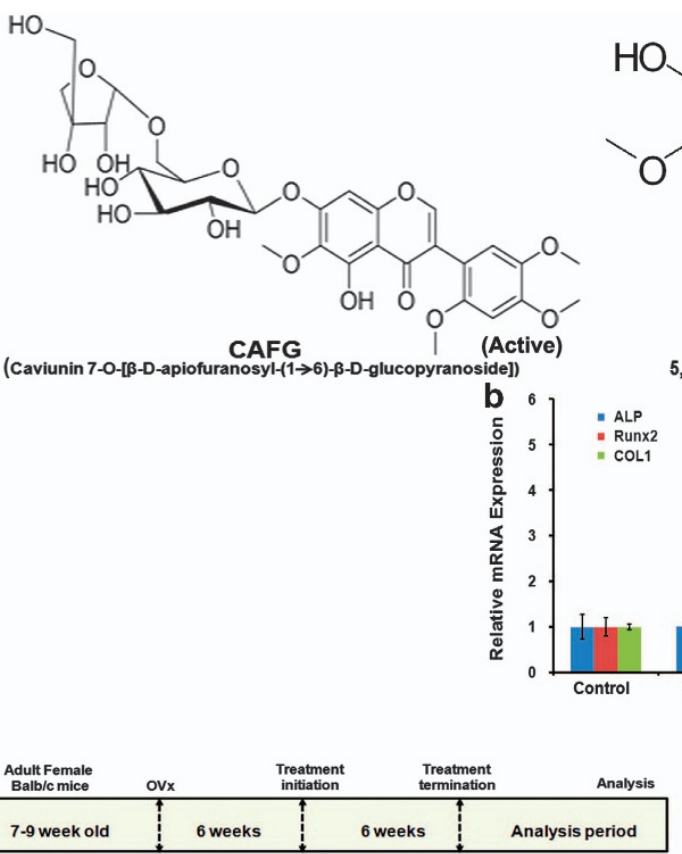

c

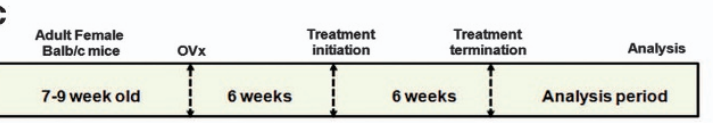

e

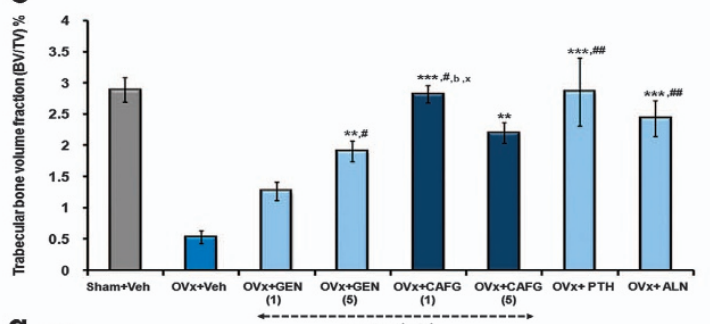

g 0.6
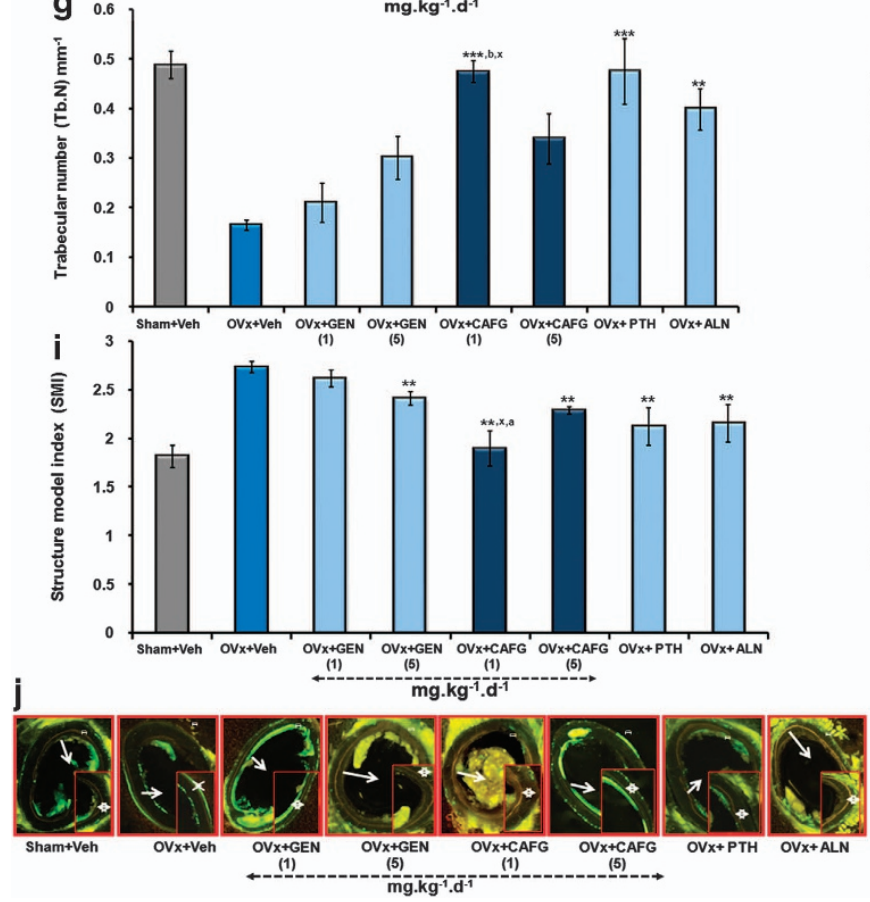

$\mathrm{HO}$<smiles>COc1cc(OC)c(-c2coc3cc(O)c(OC)c(O)c3c2=O)cc1OC</smiles>

Caviunin 5,7-Dihydroxy-6,2',4',5'-tetramethoxyisoflavone<smiles>O=c1c(-c2ccc(O)cc2)coc2cc(O)cc(O)c12</smiles>

Genistein

5,7-Dihydroxy-3-(4-hydroxyphenyl)chromen-4-one
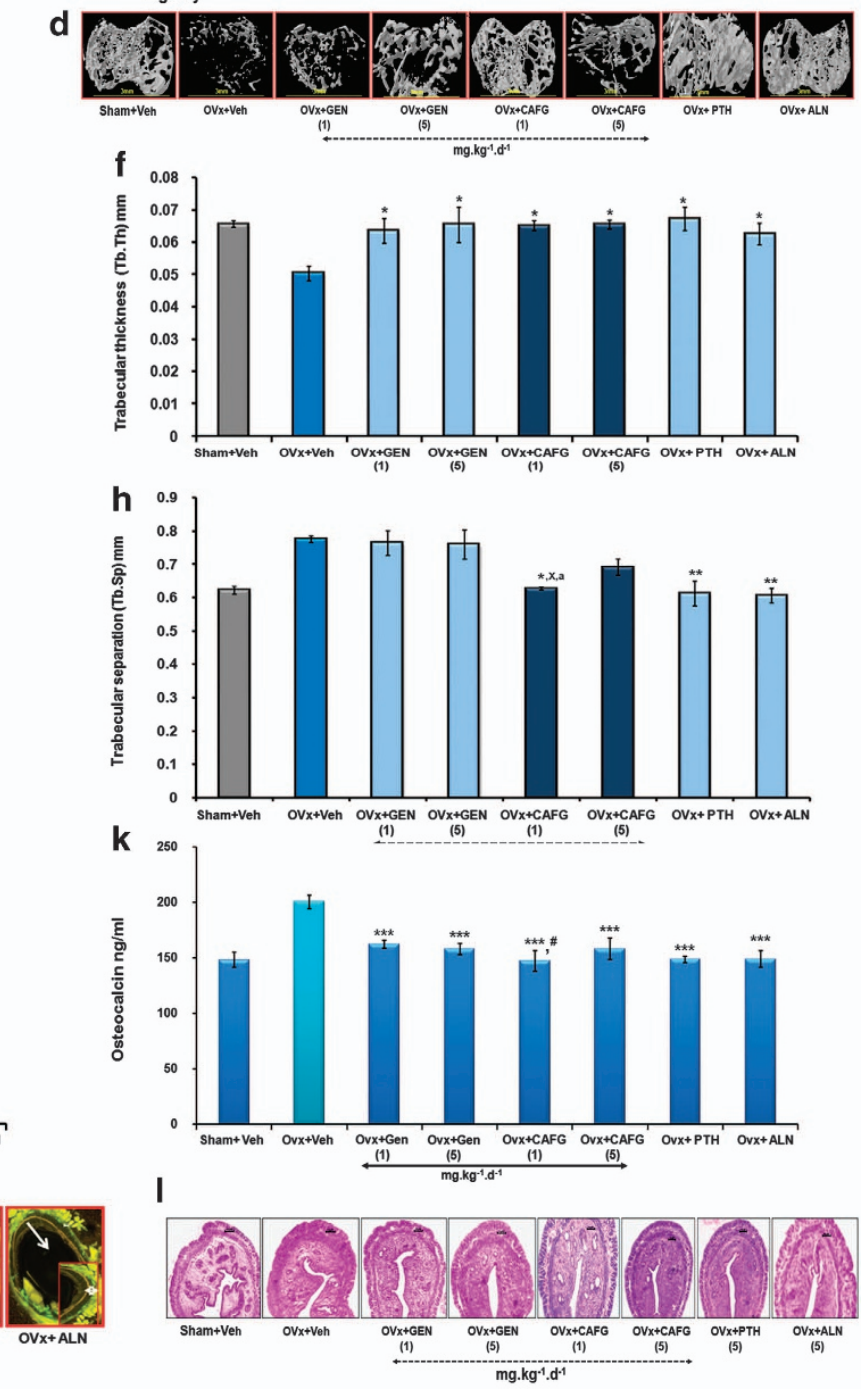
CAFG treatment reduces bone turnover markers in OVx mice. OVx-induced bone loss was characterized by higher bone turnover rates, as represented by higher levels of $\sim 33 \%$ of serum Osteocalcin (OCN) compared with the Sham group (Figure 1k). ${ }^{16}$ However, 6 weeks of CAFG treatment to OVx group significantly lowered back the levels of this marker to $\sim 30 \%$, indicating attenuation of bone turnover and thus resorption. CAFG ( $1 \mathrm{mg} / \mathrm{kg} / \mathrm{day})$ was more effective in lowering down the serum OCN levels as compared with GEN $(P<0.05$; Figure $1 \mathrm{k})$.

CAFG elicits no uterine estrogenicity. OVx resulted in reduction in all uterine parameter (wet uterine weight, luminal area and epithelial cell height), which is shown in Figure $1 \mathrm{I}^{17,18}$ These mice on treatment with either 1 or $5 \mathrm{mg} / \mathrm{kg} /$ day dose of CAFG, GEN, PTH and ALN for 6 weeks exhibited no change in uterine weight indicating no hyperplasic effect compared with OVx (Table 1).

Bone marrow cells (BMCs) after treatment with CAFG induced cell proliferation, differentiation and mineralization. CAFG increased cell proliferation at $1.0 \mathrm{mg} / \mathrm{kg} /$ day $(P<0.001)$ and GEN at $5.0 \mathrm{mg} / \mathrm{kg} /$ day $(P<0.01)$ compared with OVx group (Figure 2c) assessed by 5-Bromo-2'deoxyuridine (BrdU) assay. The measurement of cell viability and proliferation of treated BMCs revealed that all treated compound has more cell proliferation compared with $\mathrm{OVx}$ group (Figure 2c). For further experiments, $1 \mathrm{mg} / \mathrm{kg} /$ day dose for CAFG and $5 \mathrm{mg} / \mathrm{kg} /$ day dose of GEN were used. Figure $2 \mathrm{a}$ shows that BMCs from the OVx group resulting in $\sim 30 \%$ decreased differentiation of BMCs toward osteo- genic line as seen by ALP assay. CAFG at $1 \mathrm{mg} / \mathrm{kg} /$ day $(P<0.001)$ and $5 \mathrm{mg} / \mathrm{kg} / \mathrm{day}(P<0.01)$ doses significantly promoted differentiation of BMCs toward osteoblast with maximum stimulation at $1 \mathrm{mg} / \mathrm{kg} /$ day dose ( $\sim 60 \%$ ) Comparison with GEN, PTH and ALN shows that CAFG stimulates differentiation of cells comparable to the sham (Figure 2a). Data were corroborated by mineralization assay (Figure $2 b$ upper panel).

CAFG increased expression of osteogenic genes with decreased expression of osteoclastogenic genes in long bones. CAFG significantly $(P<0.01)$ increased the expression of osteogenic genes, osteoprotegerin (OPG, Figure 2d) and $O C N$ gene (Figure 2e). Analysis of expression of resorption marker gene shows that OVx resulted in increased expression of RANKL (receptor activator of nuclear factor kappaB ligand), TRAP (tartrate-resistant acid phosphatase) and RANK (receptor activator of nuclear factor kappaB). Whereas the expression was reduced by CAFG at $1 \mathrm{mg} / \mathrm{kg} /$ day, GEN at $5 \mathrm{mg} / \mathrm{kg} /$ day, PTH and ALN (Figures $2 \mathrm{f}$ and $\mathrm{g}$ ) up to Sham.

CAFG decreases enhanced resorption in ovariectomized mice. TRAP staining of decalcified tibia bone revealed a massive increase in osteoclast number (Oc/Bs) and osteoclast surface (Os/Bs) in OVx group, which significantly recovered after treatment with $\mathrm{CAFG}$ and GEN. CAFG at $1 \mathrm{mg} / \mathrm{kg} /$ day dose has decreased osteoclast number $(P<0.01)$ and osteoclast surface area $(P<0.01)$, which is comparable to positive control groups (Figures 2h-j).

Table 1 Effects of various treatment groups for 6 weeks on different bone parameters of osteopenic mice

\begin{tabular}{|c|c|c|c|c|c|c|c|c|}
\hline Parameters & $\begin{array}{l}\text { Sham + veh } \\
\text { (gum-acacia) }\end{array}$ & $\begin{array}{c}\text { OVx }+ \text { veh } \\
\text { (gum-acacia) }\end{array}$ & $\begin{array}{c}\text { OVx }+ \text { GEN } \\
(1 \mathrm{mg} / \mathrm{kg})\end{array}$ & $\begin{array}{c}\text { OVx + GEN } \\
(5 \mathrm{mg} / \mathrm{kg})\end{array}$ & $\begin{array}{c}\text { OVx }+ \text { CAFG } \\
(1 \mathrm{mg} / \mathrm{kg})\end{array}$ & $\begin{array}{c}\text { OVx }+ \text { CAFG } \\
(5 \mathrm{mg} / \mathrm{kg})\end{array}$ & $\begin{array}{l}\text { OVx }+ \text { PTH } \\
(40 \mu \mathrm{g} / \mathrm{kg})\end{array}$ & $\begin{array}{l}\text { OVx }+ \text { ALN } \\
(3 \mathrm{mg} / \mathrm{kg})\end{array}$ \\
\hline \multicolumn{9}{|l|}{ Biomechanical strength of femur } \\
\hline $\begin{array}{l}\text { Stiffness }(\mathrm{N} / \mathrm{mm}) \\
\text { Energy }(\mathrm{mj})\end{array}$ & $\begin{array}{l}75.4 \pm 10.1^{c} \\
5.86 \pm 0.83^{b}\end{array}$ & $\begin{array}{l}19.6 \pm 2.2 \\
2.22 \pm 0.25\end{array}$ & $\begin{array}{l}41.5 \pm 11.4^{\mathrm{a}} \\
4.56 \pm 0.22^{\mathrm{b}}\end{array}$ & $\begin{array}{l}56.8 \pm 9.5^{\mathrm{a}} \\
6.22 \pm 0.57^{\mathrm{b}}\end{array}$ & $\begin{array}{l}69.9 \pm 6.7^{\mathrm{c}} \\
6.94 \pm 0.83^{\mathrm{b}}\end{array}$ & $\begin{aligned} 52.5 & \pm 3.9^{\mathrm{a}} \\
6.8 & \pm 0.32^{\mathrm{b}}\end{aligned}$ & $\begin{aligned} 52.8 & \pm 2.9^{\mathrm{a}} \\
6.6 & \pm 0.36^{\mathrm{b}}\end{aligned}$ & $\begin{array}{l}47.1 \pm 5.6^{\mathrm{a}} \\
5.78 \pm 1.43^{\mathrm{b}}\end{array}$ \\
\hline \multicolumn{9}{|c|}{ Biomechanical strength of lumber-5 (L-5) vertebrae } \\
\hline Stiffness $(\mathrm{N} / \mathrm{mm})$ & $324.5 \pm 38.1^{\mathrm{b}}$ & $163.9 \pm 11$ & $314.5 \pm 35.4^{\mathrm{b}}$ & $320.3 \pm 25.3^{b}$ & $344.2 \pm 28.3^{\mathrm{b}}$ & $332.5 \pm 20.6^{\mathrm{b}}$ & $346.3 \pm 20^{b}$ & $345.8 \pm 18.7^{b}$ \\
\hline Energy (mj) & $387.3 \pm 23^{\mathrm{c},+}$ & $229.5 \pm 12.4$ & 299.6 & $324.2 \pm 18.1^{a}$ & 411.3 & $406.4=$ & $396.4 \pm 12.6^{\mathrm{c},+}$ & $418.5 \pm 10.5^{c_{1}+}$ \\
\hline \multicolumn{9}{|c|}{ Dynamic histomorphometric measurement at femur diaphysis } \\
\hline MAR $(\mu \mathrm{m} /$ day $)$ & $0.27 \pm 0.027^{b}$ & $0.15 \pm 0.012$ & $0.22 \pm 0.02$ & $0.24 \pm 0.014^{a}$ & $0.26 \pm 0.016^{\mathrm{a}}$ & $0.24 \pm 0.03^{\mathrm{c}}$ & $0.36 \pm 0.013^{c}$ & $0.20 \pm 0.010$ \\
\hline BFR/BS $\left(\mu \mathrm{m}^{3} \mu \mathrm{m}^{2} /\right.$ day $)$ & $0.29 \pm 0.02^{\mathrm{C}}$ & $0.10 \pm 0.01$ & $0.20 \pm 0.02^{b}$ & $0.26 \pm 0.01^{\mathrm{c}}$ & $0.29 \pm 0.008^{\mathrm{C}}$ & $0.25 \pm 0.02^{c}$ & $0.33 \pm 0.01^{\mathrm{c}}$ & $0.16 \pm 0.009$ \\
\hline \multicolumn{9}{|l|}{ Uterine Parameters } \\
\hline Uterine wt. (mg) & $0.13 \pm 0.009$ & $0.02 \pm 0.003^{z}$ & $0.05 \pm 0.008^{z}$ & $0.03 \pm 0.004^{z}$ & $0.033 \pm 0.004^{z}$ & $0.04 \pm 0.003^{z}$ & $0.028 \pm 0.003^{z}$ & $0.02 \pm 0.003^{z}$ \\
\hline Total uterine area $\left(\mu \mathrm{m}^{2}\right)$ & $5883.6 \pm 134.3$ & $783.4 \pm 20.6^{z}$ & $959.4 \pm 28.8^{z}$ & $927.8 \pm 44.7^{z}$ & $799 \pm 26.7^{z}$ & $865.2 \pm 20.3^{\mathrm{z}}$ & $865.1 \pm 39.05^{z}$ & $881.8 \pm 65.1^{z}$ \\
\hline Luminal area $\left(\mu \mathrm{m}^{2}\right)$ & $507.4 \pm 5.9$ & $62.6 \pm 3.9^{z}$ & $76 \pm 2.6^{z}$ & $70.3 \pm 5.2^{z}$ & $61.3 \pm 5.7^{z}$ & $66.6 \pm 3.2^{z}$ & $65 \pm 8.6^{z}$ & $68 \pm 1.5^{z}$ \\
\hline Luminal epithelial cell height $(\mu \mathrm{m})$ & $1.51 \pm 0.09$ & $0.58 \pm 0.02^{z}$ & $0.77 \pm 0.03^{z}$ & $0.65 \pm 0.07^{z}$ & $0.58 \pm 0.03^{z}$ & $0.61 \pm 0.04^{z}$ & $0.58 \pm 0.04^{z}$ & $0.64 \pm 0.04^{z}$ \\
\hline
\end{tabular}

${ }^{\mathrm{a}} P<0.05,{ }^{\mathrm{b}} P<0.01,{ }^{\mathrm{c}} P<0.001$ versus $\mathrm{OVx} ;{ }^{\mathrm{z}} P<0.001$ versus Sham, ${ }^{+} P<0.05$, versus GEN $1 \mathrm{mg}$

\footnotetext{
Figure 2 CAFG enhances osteoblast mineralization through inhibitory effect of osteoclastogenesis. (a) Ex vivo experiments show that CAFG stimulates osteoblast proliferation and early differentiation assessed by ALP activity. Values represent mean $\pm \mathrm{S}$.E. ${ }^{\star} P<0.05,{ }^{* \star} P<0.01,{ }^{* \star *} P<0.001$ versus OVx. ${ }^{\#} P<0.05$ versus GEN $1 \mathrm{mg} / \mathrm{kg} /$ day. (b) Oral supplementation of CAFG to OVx mice increased mineralized nodule formation in BMCs as assessed by Alizarin Red-S staining. Lower panel showed quantification of alizarin staining. Values represent mean \pm S.E. ${ }^{*} P<0.05,{ }^{* *} P<0.01,{ }^{* *} P<0.001$ versus $0 \mathrm{Vx} ;{ }^{\#} P<0.05,{ }^{\#} P<0.01,{ }^{\# \#} P<0.001$ versus GEN $1 \mathrm{mg} / \mathrm{kg} / \mathrm{day}$. (c) Effect of CAFG on bone marrow cell proliferation of various treatment groups using BrdU incorporation cell proliferation assay. Values represent mean \pm S.E. of three independent experiments $(n=3) .{ }^{* \star} P<0.01,{ }^{\star \star \star} P<0.001$ when compared with OVx group. (d-f) Effect of CAFG on osteoclastogenesis and osteoblastogenesis marker in bone. CAFG enhanced mRNA levels of OPG (d), OCN, (e) expression but decrease mRNA levels of RANKL (f), TRAP and RANK (g) quantified with Q-PCR and normalized with GAPDH. Values represent mean \pm S.E. ${ }^{\star} P<0.05$, ${ }^{\star *} P<0.01,{ }^{* \star \star} P<0.001$ versus $\mathrm{OVx} ;{ }^{\#} P<0.05,{ }^{\# \#} P<0.01,{ }^{\# \# \#} P<0.001$ versus GEN $1 \mathrm{mg} / \mathrm{kg} /$ day. (h) Representative images of TRAP staining in tibia bone. Quantitative estimation of osteoclast number (i) and osteoclast surface (j). Values represent mean \pm S.E. ${ }^{* *} P<0.01$ versus $\mathrm{OVx}$
} 
CAFG promoted extracellular matrix synthesis in vitro. We have examined the ability of CAFG to modulate chondrogenesis in this experiment. CAFG induce proliferation of chondrocytes at day 2 , but by day 4 , proliferation increased at $1.0 \mu \mathrm{M}$ concentration of CAFG, with the highest being at $10 \mathrm{nM}(P<0.001)$ as assessed by

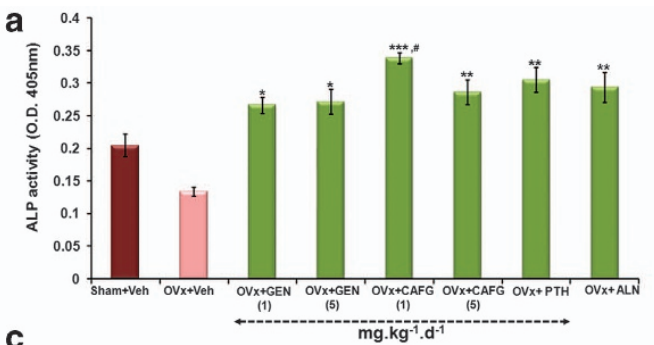

b
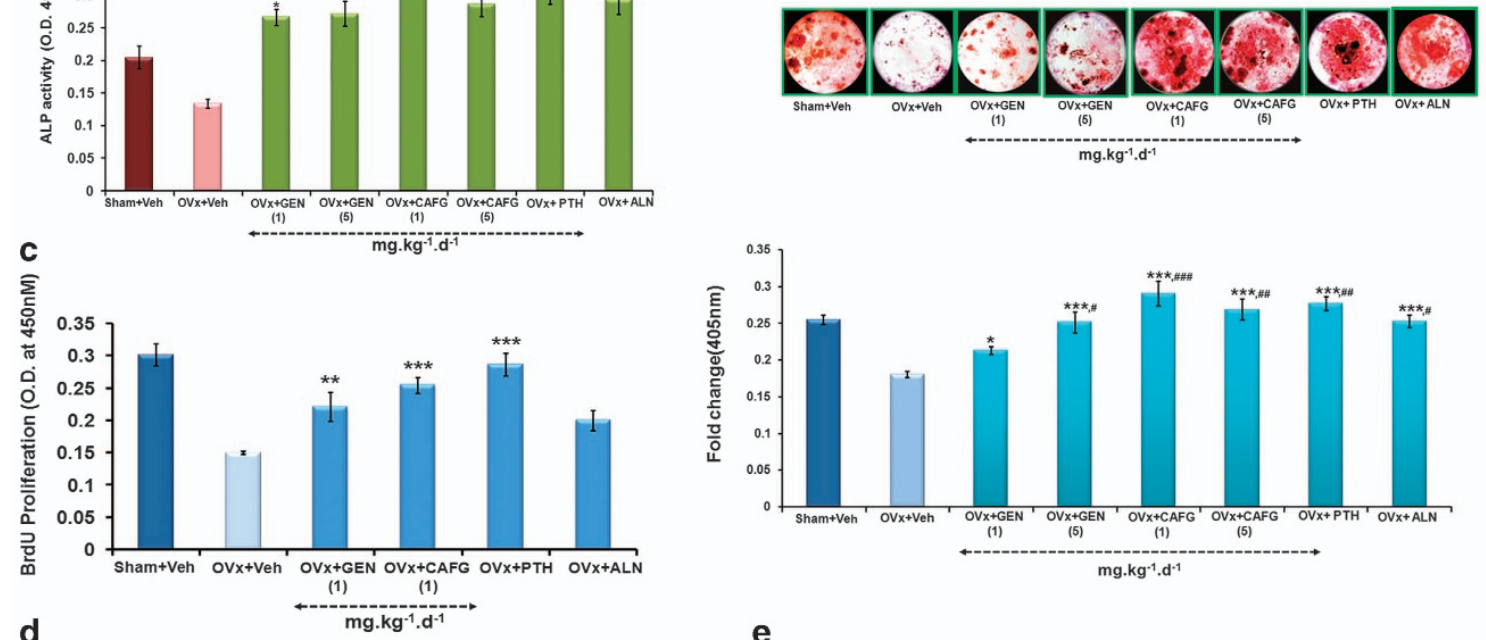

d

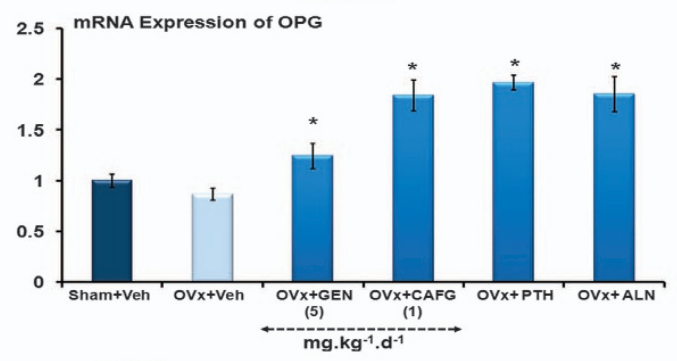

e

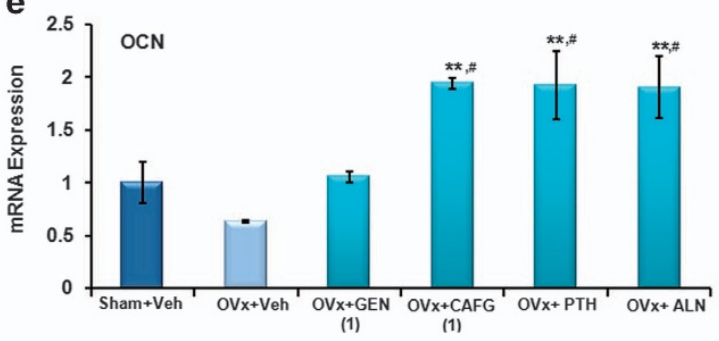

$\mathbf{f}$
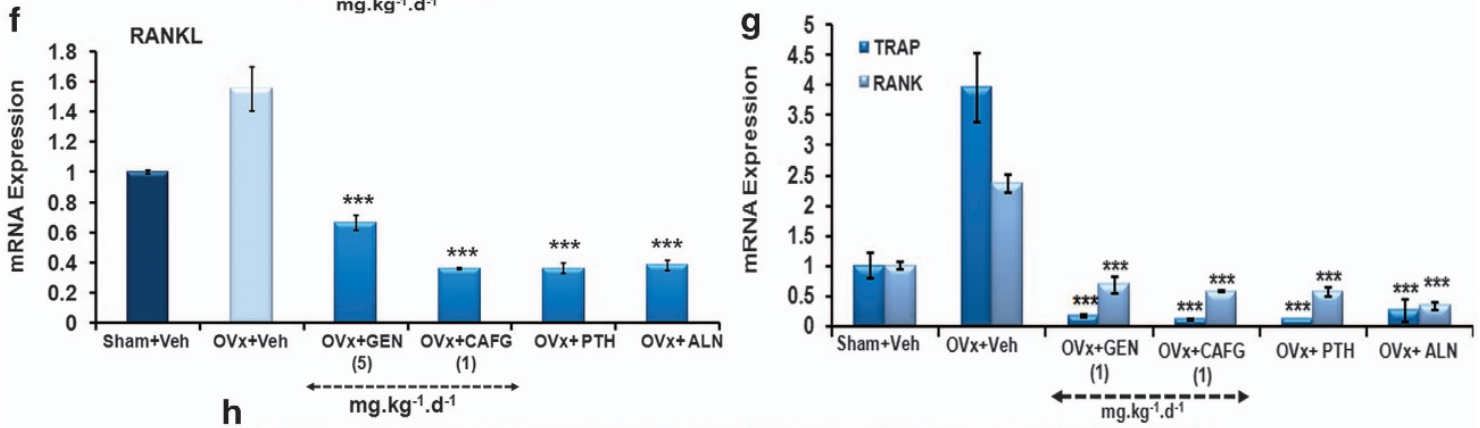

h

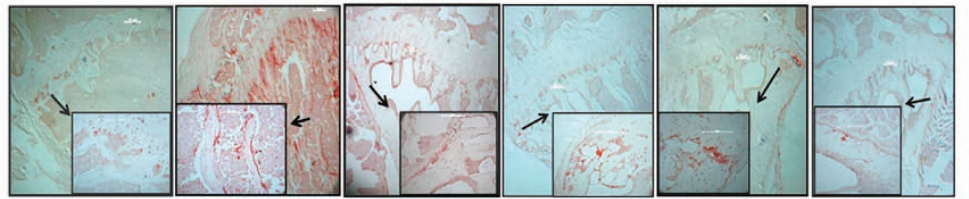

Sham+Veh OVx+Veh

\begin{tabular}{cc} 
OVx+GEN & OVx+CAFG \\
$(1)$ & $(1)$ \\
\hdashline$-m \cdot g^{-1} \cdot d^{-1}$
\end{tabular}
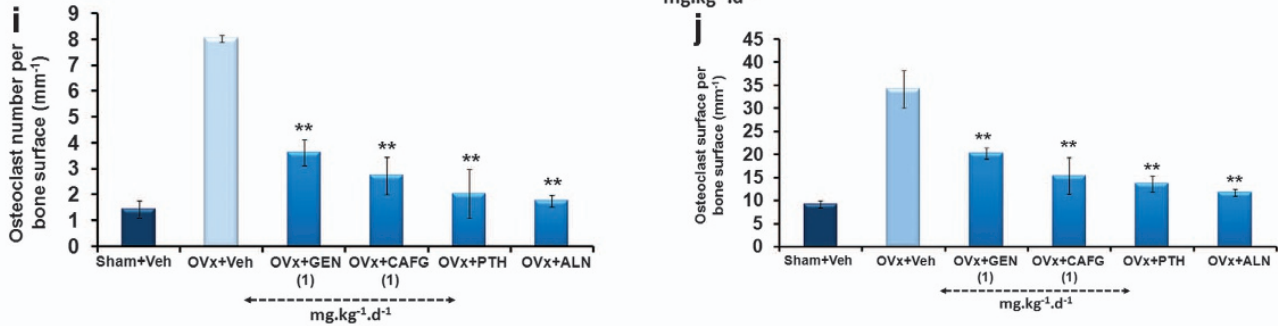


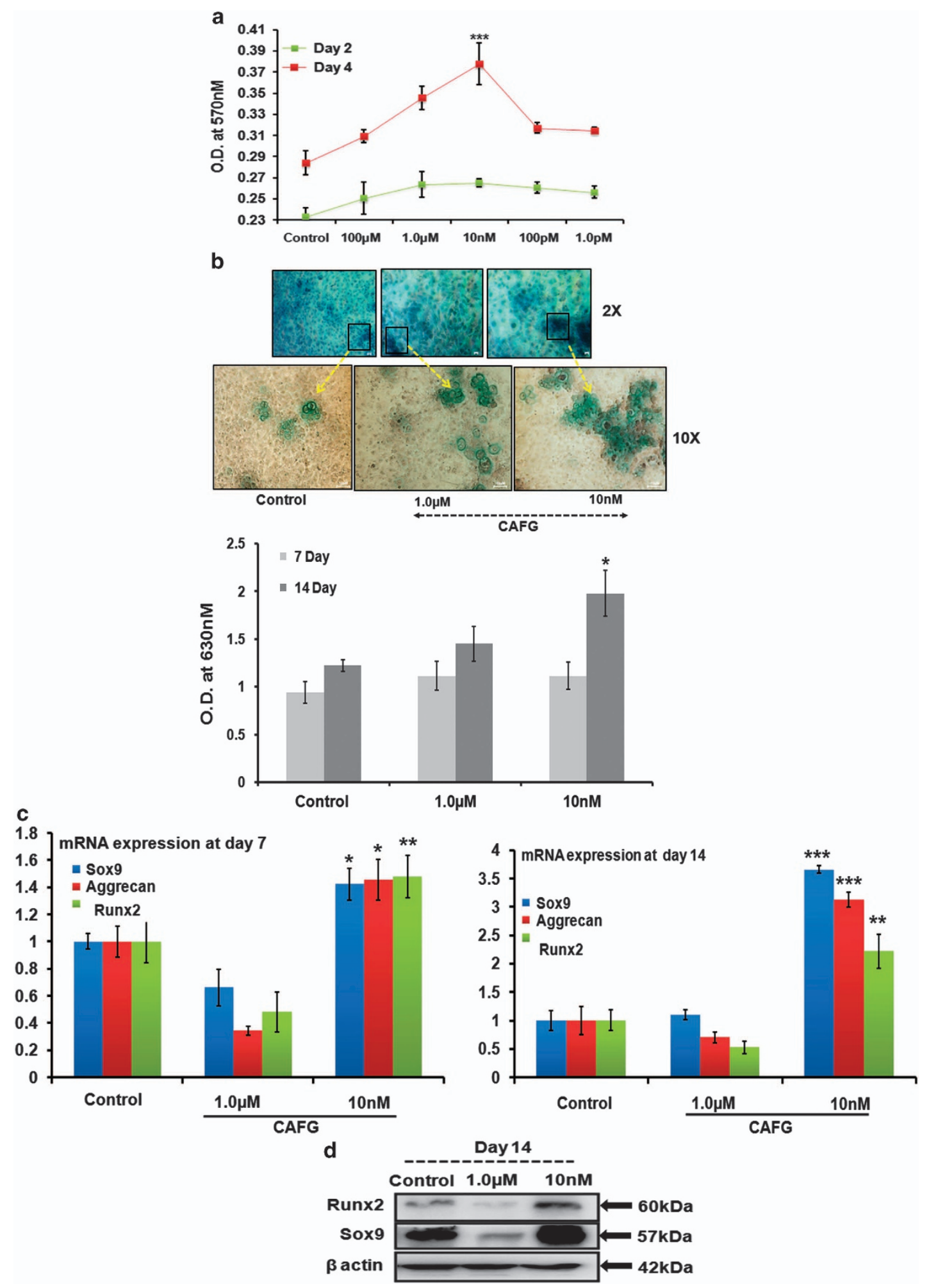

b

Figure 3 CAFG promotes proliferation and gene expression of chondrocytes. (a) Cytotoxicity analysis of CAFG at different concentrations at day 2 and 4 on chondrocytes. (b) Measurement of chondrogenesis in showing dose dependent and time dependent. Cells were fixed with $4 \%$ paraformaldehyde. After fixation, cell layers were stained with $0.5 \%$ alcian blue stain in $0.1 \mathrm{~N} \mathrm{HCl}$ and rinsed, the extracted dye was quantified. Intensity of alcian blue staining measured at $630 \mathrm{nM}$. Data represent mean $\pm S$.E. ${ }^{* \star} P<0.01$, ${ }^{* * *} P<0.001$ compared with control. (c) Quantitative expression of chondrocyte-expressing genes by Q-PCR. The chondrocytes were cultured in different concentrations of CAFG for days 7 and 14. Values represent mean \pm S.E. from three independent experiments. ${ }^{*} P<0.05,{ }^{* *} P<0.01,{ }^{* *} P<0.001$ compared with control and the data normalized with internal control GAPDH. (d) Protein expression of protein specific to chondrocytes by western blot on day 14 . The data normalized with internal control $\beta$-actin 
using MTT (3-(4, 5-dimethylthiazol-2-yl)-2, 5-diphenyltetrazolium bromide) in articular chondrocytes from newborn mice pups (1- to 2-day old) ${ }^{19}$ (Figure $3 a$ ). At $100 \mathrm{pM}$ or $1.0 \mathrm{pM}$, increase in proliferation was plateau off. Overall, CAFG was not toxic to the chondrocytes. Estimation of the chondrogenic effect was done by micro-mass culture. Alcian blue staining specific for chondrocytes (Figure $3 b$ ) shows that with CAFG treatment at $1.0 \mu \mathrm{M}$ and $10 \mathrm{nM}$ there is a greater deposition of proteoglycans and increased chondrogenic activity by day 14 , whereas by day 7 , there are no changes in the cells (Figure 3b). Quantitative real-time PCR (Q-PCR) assessment of cartilage-specific genes Sox9 (early chondrogenic marker), ${ }^{20}$ aggrecan (cartilage-specific proteoglycan core protein) $^{21}$ and Runx2 (proliferates chondrocytes), ${ }^{22}$ at days 7 and 14 post CAFG treatment shows that $10 \mathrm{nM}$ concentration significantly increased the expression of all the three genes as compared with the $1.0 \mu \mathrm{M}$ concentration (Figure 3c). Data were further corroborated at the protein level for Sox9 and Runx2 (Figure 3d). Overall, in vitro data imply that CAFG is an effective accelerant for chondrogenesis, which was further tested in the in vivo system.

CAFG accelerated repair of cortical bone after drill-hole injury in mouse. Our in vitro data in chondrocytes suggested that CAFG could have a potential in fracture healing. Therefore, doses of 1 and $5 \mathrm{mg} / \mathrm{kg} /$ day were tested in the drill hole as shown in Figure 4a. For confirmation of osteoporotic bone before generation of drill-hole defect, micro-computed tomography $(\mu-\mathrm{CT})$ was performed ${ }^{23}$ that shows that OVx mice have less trabecular bone, disorganized trabecular structure and thinning of cortical bones compared with Sham mice (data shown in Table 2). CAFG treatment at doses of 1 and $5 \mathrm{mg} / \mathrm{kg} /$ day increased mineral deposition (measured from the intensity of calcein labeling in the drill hole; Figures $4 b$ and $c$ ) as early as 11th day post fracture as compared with controls (day 0; Figure 4c). The OVx group with drill hole showed the same effect in response to CAFG treatment but bone formation was significantly less when compared with Sham group (Figure 4c). Data were verified by $\mu$-CT of drill-hole area (Figure 4d), which showed 2D and 3D images generated by $\mu$-CT with increased BV/TV and Tb.No and decreased Tb.Sp. and SMI evidenced by significantly more callus being formed in the drill hole after CAFG treatment as early as on day 11th (Figures $4 \mathrm{e}$ and f). It led to predominantly occupied mineralized callus, and the defect region was partially bridged in the Sham groups. But as compared with the $5 \mathrm{mg} / \mathrm{kg} /$ day, $1 \mathrm{mg} / \mathrm{kg} /$ day had significantly more effect. Rate of callus formation of Sham group versus the OVx group shows that OVx mice had lower mineral deposition (39.0\% less) than the Sham group; however, within the OVx group, CAFG at both the doses of 1 and $5 \mathrm{mg} /$ $\mathrm{kg} /$ day increased mineral deposition. Results were consistent with Q-PCR data with increased expression of osteogenic genes Runx2, BMP2, BMP4, OCN and COL1 mRNA (Figure $4 \mathrm{~g}$ ). Expression of genes peaked significantly with $1 \mathrm{mg} / \mathrm{kg} /$ day on day 11 as compared with the $5 \mathrm{mg} / \mathrm{kg} /$ day dose. Increased mRNA expression of OCN was complimented with the increased serum levels of OCN (Figure 4h). Overall, CAFG significantly contributed to the healing process in bone as observed in both Sham and OVx group.
CAFG reduces apoptosis of osteoblast cells. Data of fluorescence-activated cell sorting (FACS) following Annexin-V/PI staining (Figure 5a) show that CAFG treatment to these cells attenuated the number of apoptotic cells to $\sim 4 \%$ (Figure $5 \mathrm{~b}$ ) compared with $12 \%$ apoptotic cells in $0.5 \%$ FCS. Data also suggest that CAFG has the ability to rescue cells undergoing early apoptosis as compared with the cells that are late apoptotic or have become necrotic.

Effects of CAFG on p38 mitogen-activated protein kinase (MAPK) activation and BMP2 secretion in osteoblasts. CAFG stimulated osteoblast differentiation by increasing ALP production (Figure $5 \mathrm{c}$ ). This ALP activity was completely inhibited by p-38 MAPK inhibitor SB203580. Consistent with the observation that SB203580 blocked CAFG-induced ALP activity in osteoblast. CAFG stimulated phosphorylation of $\mathrm{p}-38$ MAPK as early as at $12 \mathrm{~h}$ and attaining peak phosphorylation at $24 \mathrm{~h}$ (Figure $5 \mathrm{~d}$ ), these findings were corroborated by western blot analysis at the same time points (Figure 5e). CAFG increased BMP2 expression, a potent stimulator of osteogenesis in timedependent manner with the maximum stimulation being at $24 \mathrm{~h}$ (Figure 5f). CAFG-induced BMP2 expression was inhibited in the presence of noggin (an endogenous BMP2 antagonist) at mRNA, protein and secreted BMP2 levels in conditioned media (Figures $5 \mathrm{~g}-\mathrm{i}$ ). Assessment of BMP2-dependent genes in the presence of CAFG shows that Smad1 and ALP expression levels were abrogated by noggin in mice calvarial osteoblast cells (Figure $5 \mathrm{j}$ ), indicating that CAFG-induced Smad-1 phosphorylation (Figure 5I) is BMP2 dependent. Further, since BMP function activates Smad-1 proteins to stimulate expression of target gene Runx2. We used mouse full-length dual luciferase reporter system to test the effects on osteogenic differentiation in response to CAFG (Figure 5k). Our data show that CAFG induced the osteogenic activity as early as $6 \mathrm{~h}$ by activation of pRunx2Luc promoter of osteoblast in time-dependent manner that was maintained upto $24 \mathrm{~h}$ as evident also at protein level (Figures $5 \mathrm{k}$ and $\mathrm{I}$ ). To prove that CAFG stimulation is dependent on MAPK activation, we checked BMP2 expression in the presence of SB203580 that significantly attenuated the CAFG-induced increase in BMP2 expression from osteoblast (Figure $5 \mathrm{~m}$ ), suggesting that MAPK activation is a prior event than BMP2 expression. Together, data presented demonstrate that CAFG induces BMP2 secretion via the $p-38$ MAPK pathway in osteoblasts and the resultant increase in the secreted BMP2 in turn may lead to osteoblast differentiation in a para/autocrine manner.

CAFG induced osteoblastic protein via canocincal $\mathbf{W n t} / \boldsymbol{\beta}$-catenin signaling. Evidences suggest that Wnt signaling pathway modulates differentiation, proliferation and mineralization in bone formation as a downstream of BMP. ${ }^{24,25}$ CAFG at $10 \mathrm{nM}$ concentration significantly induced the expression of Wnt3a, Lrp5, GSK3 $\beta$ and $\beta$-catenin and significantly attenuated the expression of Dkk1, sclerostin and phosphorylated GSK3 $\beta$ levels in cultured osteoblast cells (Figure 6a). The above results were corroborated by expression seen at the protein level and quantitation of the same by densitometric analysis (Figures $6 \mathrm{~b}$ and $\mathrm{c}$ ). 

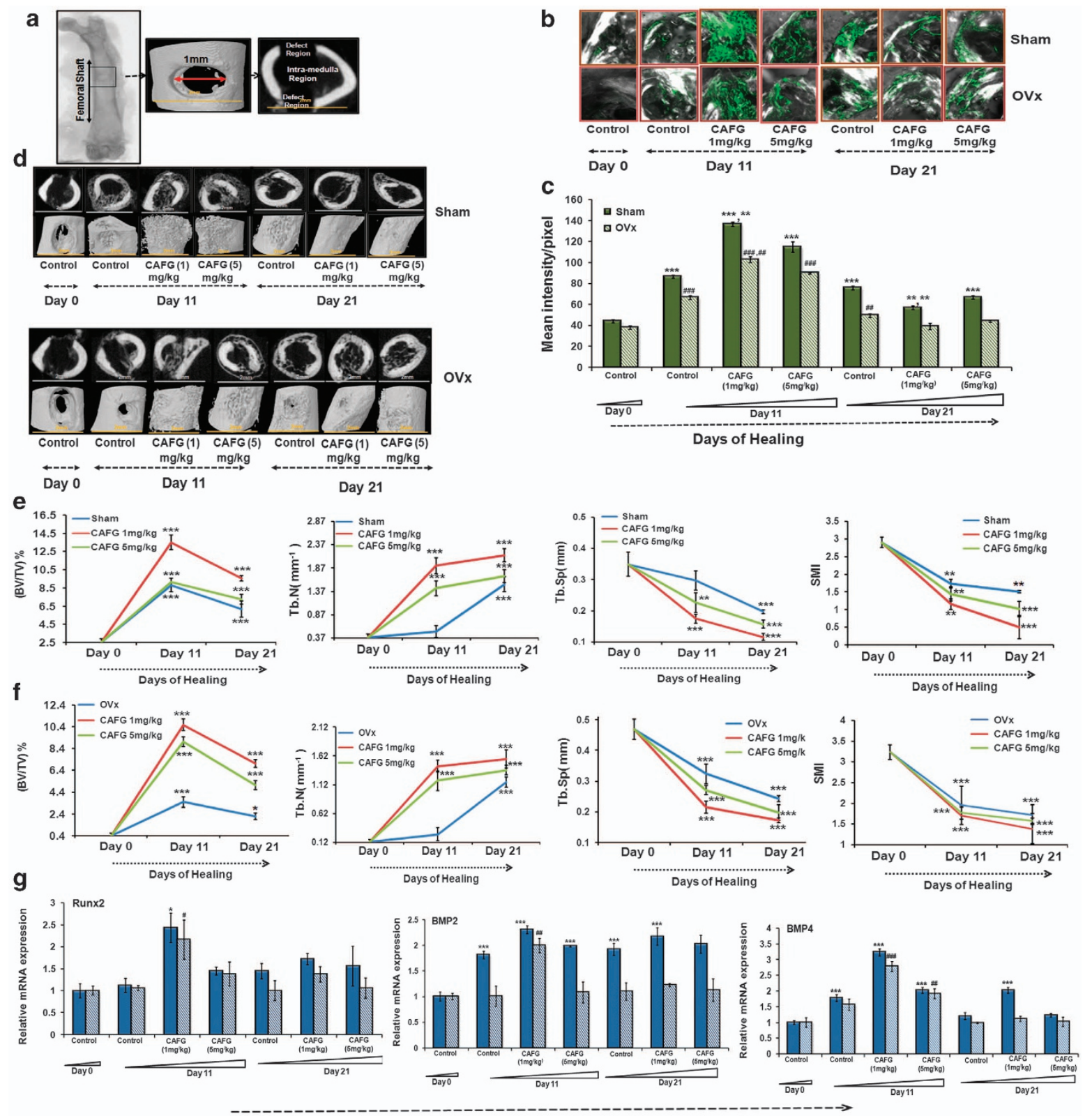

Days of Healing
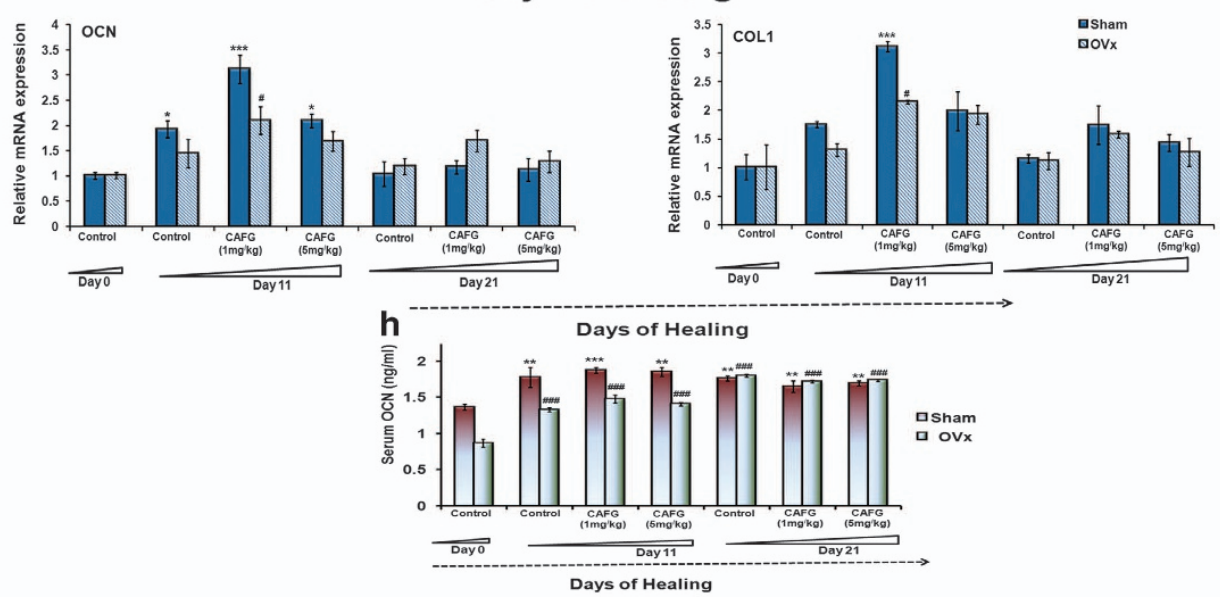
Fluorescence labeling data show that CAFG-induced nuclear localization of $\beta$-catenin required for transcription of target genes. BMP inhibitor noggin alone or in the presence of CAFG (increased when compared with noggin alone) blocked CAFG-induced nuclear localization of $\beta$-catenin in osteoblast cells, implying that BMPs mediate the nuclear localization of $\beta$-catenin induced by CAFG (Figure $6 \mathrm{~d}$ ). Nuclear localization of $\beta$-catenin was quantified by western blot analysis (Figure 6e) showing that nuclear/cytoplasmic ratio was significantly higher with CAFG treatment as compared with that of noggin alone or CAFG+ noggin treatment (Figure 6f). Osteoblasogenesis by CAFG through activation of $\beta$-catenin/Wnt signaling was confirmed by blocking it by exogenous addition of recombinant Dkk1 (Figures 6g-i). Another small-molecule inhibitor $\mathrm{FH} 535$, of $\beta$-catenin/TCF complex formation treatment for $24 \mathrm{~h}$ shows that $\mathrm{FH} 535$ resulted in $60-70 \%$ inhibition of Wnt3a, BMP2 and $\beta$-catenin protein expression (Figures $6 \mathrm{j}-\mathrm{I}$ ). These results suggest that FH535 effectively repressed transcriptional and translational activity of $\beta$-catenin and therefore its downstream targets. Further, as a consequence of activation of $\beta$-catenin signaling and its stabilization, it increased TCF-based reporter gene activity

Table 2 Micro-CT analysis and mechanical testing of intact femurs from Sham and OVx mice at 6 weeks post ovary surgery

\begin{tabular}{|c|c|c|}
\hline Parameters & Sham & OVx \\
\hline \multicolumn{3}{|c|}{ Micro-CT analysis of distal femur } \\
\hline $\mathrm{BV} / \mathrm{TV}(\%)$ & $3.80 \pm 0.29$ & $1.91 \pm 0.21^{\star \star \star}$ \\
\hline Tb.Th (mm) & $0.06 \pm .002$ & $0.04 \pm 0.005^{\star *}$ \\
\hline Tb.N (m/m) & $2.28 \pm 0.14$ & $1.17 \pm 0.16^{\star \star \star}$ \\
\hline Tb.Sp. (mm) & $0.39 \pm 0.012$ & $0.58 \pm 0.02^{\star \star \star}$ \\
\hline SMI & $1.63 \pm 0.04$ & $2.42 \pm 0.10^{\star \star \star}$ \\
\hline Conn.Dn $\left(1 / \mathrm{mm}^{3}\right)$ & $70.32 \pm 3.35$ & $36.13 \pm 3.43^{\star \star \star}$ \\
\hline \multicolumn{3}{|c|}{ Micro-CT analysis of femoral shaft } \\
\hline BV/TV (\%) & $52.36 \pm 0.51$ & $47.92 \pm 1.28^{*}$ \\
\hline $\mathrm{T} . \mathrm{Ar}\left(\mathrm{mm}^{2}\right)$ & $1.76 \pm 0.04$ & $1.64 \pm 0.12^{\star}$ \\
\hline Cs.Th (mm) & $0.24 \pm 0.0$ & $0.18 \pm 0.01$ * \\
\hline B. $\operatorname{Ar}\left(\mathrm{mm}^{2}\right)$ & $0.86 \pm 0.02$ & $0.70 \pm 0.06^{\star}$ \\
\hline B.Pm (mm) & $8.79 \pm 0.25$ & $7.27 \pm 0.40^{\star \star}$ \\
\hline \multicolumn{3}{|c|}{ Mechanical testing of femoral shaft } \\
\hline Maximum power $(\mathrm{N})$ & $32.16 \pm 2.89$ & $20.66 \pm 4.07^{*}$ \\
\hline Energy (mJ) & $5.76 \pm 0.68$ & $3.11 \pm 0.30^{\star}$ \\
\hline Stiffness (N/mm) & $58.51 \pm 2.26$ & $45.76 \pm 3.11^{\star \star}$ \\
\hline
\end{tabular}

$N=6$

${ }^{\star} P<0.05,{ }^{* *} P<0.01,{ }^{\star * *} P<0.001$ for significant difference between the Sham and OVx groups
(Figure $6 \mathrm{~m}$ ). This increased activity and expression of Wntresponsive genes strongly support the mechanism for CAFG mediated by the BMP2-Wnt/ $\beta$ catenin signaling pathway.

Direct effect of CAFG on osteoclast cells. CAFG at $10 \mathrm{nM}$ concentration inhibited multinucleated TRAP-positive cells in BMCs as represented in Figures 7a and b. Q-PCR data show that addition of CAFG $(10 \mathrm{nM})$ to differentiated osteoclasts significantly downregulated the expression of TRAP $(P<0.01)$ and RANK $(P<0.05)$ mRNA expression levels (Figure 7c). Protein data corroborated the TRAP mRNA levels that were significantly downregulated as quantified by densitometry analysis (Figures $7 \mathrm{~d}$ and e). Altogether, data show that CAFG inhibited osteoclastogenesis of murine BMCs by inhibiting their differentiation and maturation. ${ }^{26}$

\section{Discussion}

Our previous study demonstrated that osteogenic effects imparted by the extract of Dalbergia sissoo in the estrogen withdrawal osteoporotic model were due to the presence of a novel analog CAFG present in maximum amount. We confirm that CAFG's ability to act as a dual acting compound stimulates osteoblast proliferation, survival and differentiation, simultaneously inhibits osteoclast formation and their differentiation in bone, suggesting positive skeletal effect.

In vivo CAFG has osteogenic effect in adult ovariectomized mice. Under the circumstance of estrogen-dependent skeletal growth, CAFG treatment resulted in dose-dependent increase in differentiation of osteoprogenitor cells and mineralization of BMCs, expected to favor bone formation. ${ }^{27}$ As a result, we observed increased MAR and BFR (resulting from expansion of bone marrow osteoblast pool) by dynamic histomorphometry in diaphysis femur of CAFG-treated mice. In agreement with dynamic histomorphometry data, $\mu$-CT (static histomorphometry) demonstrated increased trabecular bone gain by CAFG during the course of skeletal growth in mice compared with controls. Further, increased femoral periosteal bone deposition by CAFG had functional consequence in increasing bone biomechanical strength as CAFG dose-dependently increased femoral and vertebral force and stiffness. To understand detailed regulation of bone resorption, we assessed osteoclastogenesis from BMCs and bone. OVx resulted in increased resorption as seen by increased osteoclast number and activity characterizes postmenopausal bone loss. CAFG reduces the differentiation of osteoclasts around the bone surface and in vitro from BMCs comparable

Figure 4 CAFG promotes bone regeneration in the drill-hole site in Sham and OVx mice. (a) As shown $1 \mathrm{~mm}$ hole by drilling was generated in the mid-diaphysis region of the right femur bone. Defect region and intra-medulla region are clearly visible in representative two-dimensional image generated from $\mu$-CT. (b) Represents confocal images (magnification $=\times 100$ ) after calcein labeling shown in the drill-hole site of various groups and various time points 0,11 and 21 days after injury without and with CAFG treatment. (c) Data show the quantification of the mean intensity of calcein labeling at the drill-hole site. Values represent mean $\pm S . E .{ }^{*} P<0.05,{ }^{* \star} P<0.01,{ }^{* \star *} P<0.001$ compared with Sham and ${ }^{\#} P<0.05,{ }^{\# \#} P<0.01$, ${ }^{\# \# \#} P<0.001$ compared with OVx. Inter-dose comparison shows that values represent mean $\pm S$.E. ${ }^{* *} P<0.01,1 \mathrm{mg} / \mathrm{kg}$ is more significant than $5 \mathrm{mg} / \mathrm{kg}$ dose in Sham and in $\mathrm{OVx}\left({ }^{\# \#} P<0.01\right) 1 \mathrm{mg} / \mathrm{kg}$ is more significant than $5 \mathrm{mg} / \mathrm{kg}$ dose. (d) Representative 2D and 3D images generated by $\mu$-CT showing bone healing in Sham and OVx mice following drill-hole injury. (e) Quantitative assessment of bone in Sham (control) group in the defect region. Data show BV/TV, Tb.No, Tb.Sp. and SMI. Values represent mean \pm S.E. ${ }^{*} P<0.05$, ${ }^{* *} P<0.01$, ${ }^{* * *} P<0.001$ compared with day 0 . (f) Quantitative assessment of bone in $\mathrm{OVx}$ (control) group in the defect region. Data show BV/TV, Tb.No, Tb.Sp. and SMI. Values represent mean \pm S.E. ${ }^{*} P<0.05,{ }^{* *} P<0.01,{ }^{* * *} P<0.001$ compared with day 0 . (g) Expression of osteogenic and chondrogenic genes at the site of injury. Values represent mean $\pm S . E$. ${ }^{*} P<0.05,{ }^{* *} P<0.01,{ }^{* * *} P<0.001$ compared with day 0 . (h) Assessment of serum osteogenic marker osteocalcin at the end of healing process in bone. Values represent mean $\pm S . E$. ${ }^{*} P<0.05,{ }^{* \star} P<0.01,{ }^{* \star *} P<0.001$ compared with Sham and ${ }^{\sharp} P<0.05$, ${ }^{\# \#} P<0.01,{ }^{\# \# \#} P<0.001$ compared with $\mathrm{OVx}$ 
a

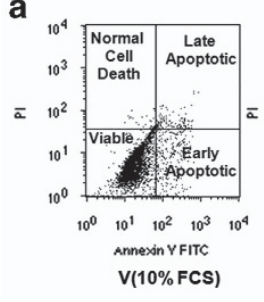

b
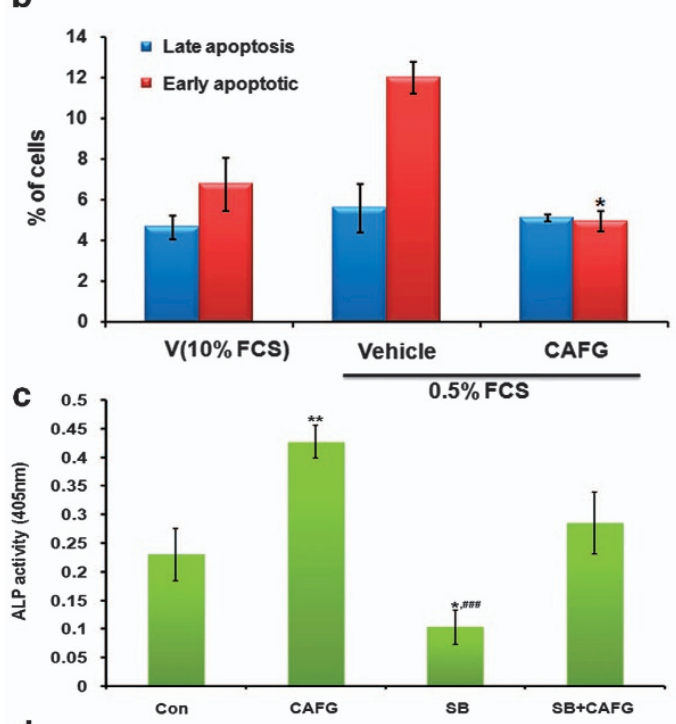

d
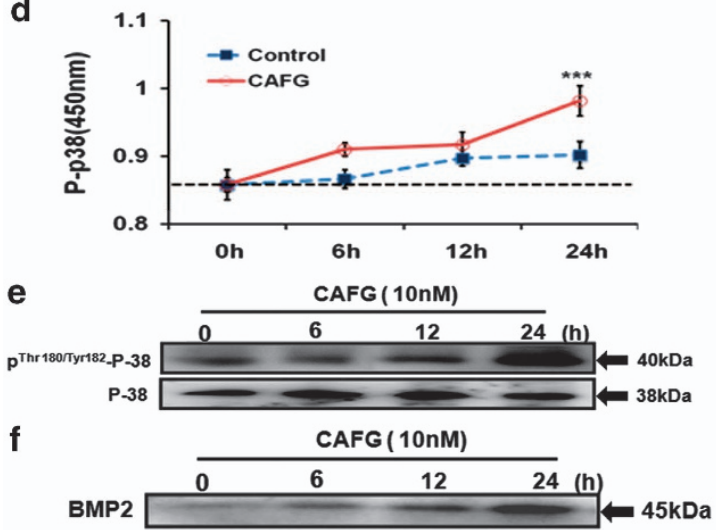

g 3.5 BMP2

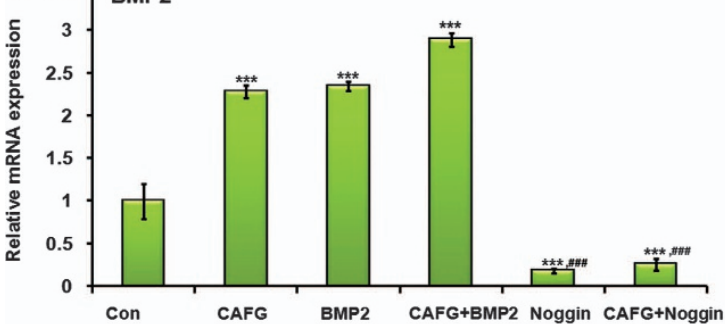

h
NAggin
BMP2
$\beta$-actin
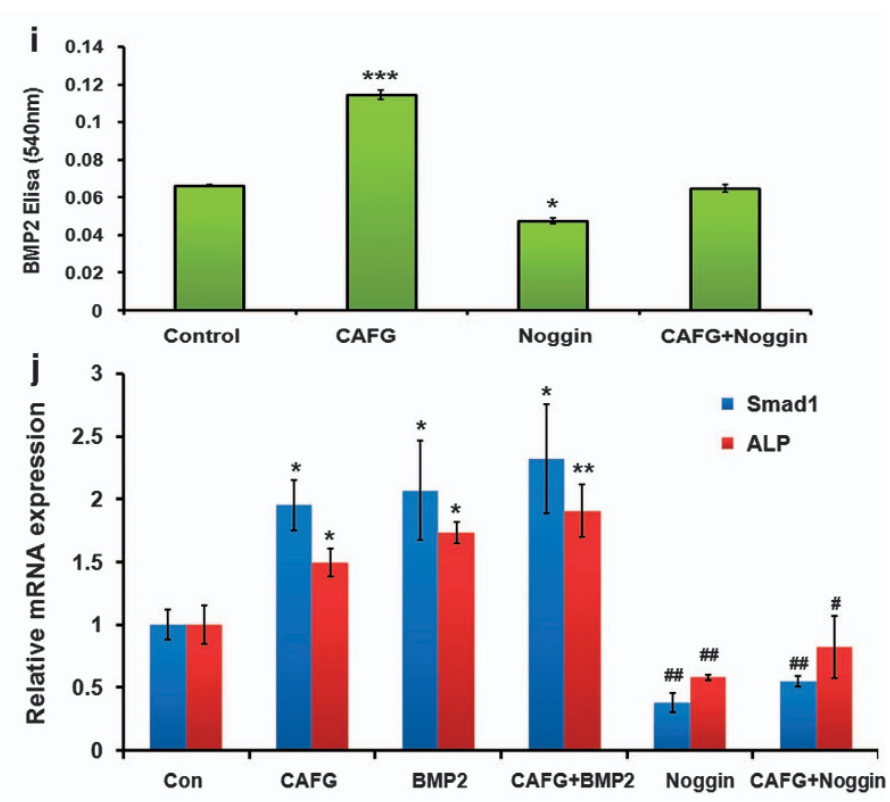

$\mathbf{k}$
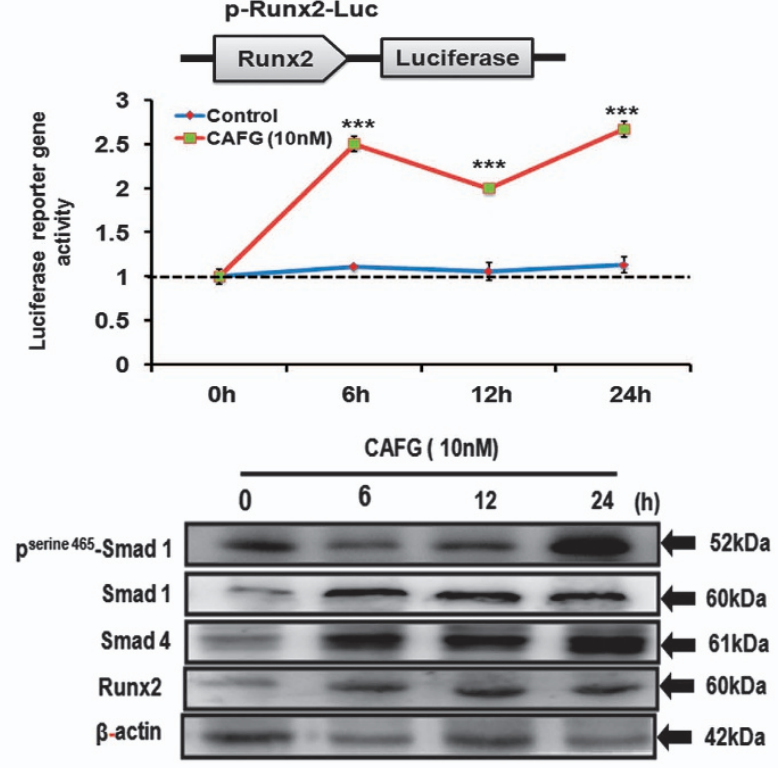

m

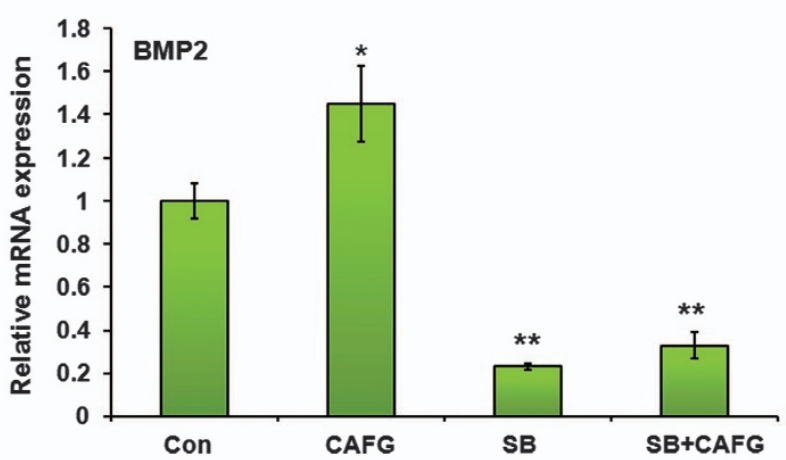


to Sham. Together, our data so far suggest that CAFG that lack uterine estrogenic effect stimulates bone formation in vivo, thus facilitating skeletal growth and acts as a dual acting compound, as it stimulates bone formation as well as inhibits bone resorption as evident by high expression of OPG and low expression of RANKL in treated group's bone marrow osteoblast cells.

CAFG has anabolic role in bone formation and primary osteoporosis in female mice. Fracture healing is a complex process and osteoporotic bone has been reported for recurrent fracture. Fracture repair includes chondrogenesis and intramembranous ossification. ${ }^{28,29}$ Therefore, we studied the effect of CAFG on chondrocyte cells to see whether it also affected the bone-healing process. CAFG at $10 \mathrm{nM}$ concentration was not toxic and increased the proliferation of chondrocyte cells by inducing expression of BMP2, SOX9 and aggrecan sequentially and then promote the synthesis of proteoglycan of chondrocyte and thus chondrogenesis. ${ }^{30-32}$ CAFG enhanced biosynthetic activities and cartilage-specific gene expression, indicating that CAFG may be a potential promoting compound for cartilage-induced injury-like fracture or tissue engineering.

As drill-hole injury model of long bone seems suitable for analyzing the healing process quantitatively and investigating chondrocyte differentiation in vivo. ${ }^{23,33,34}$ Our data, by fluorochrome labeling, show that bone regeneration in the drill hole was diminished in OVx mice, compared with Shamoperated group, which could be due to the reduced osteoblast function under estrogen deficiency. The same study showed that CAFG treatment of either Sham or OVx mice significantly augmented the process of filling up by newly generated bone in the drill hole. This finding was complemented by several $\mu$ CT parameters (BV/TV, Tb.Th, Tb.No., Tb.Sp. and SMI) that indicated a more compact assembly and preferred plate-like structure (low SMI) of the newly formed bone of CAFG-treated mice. Overall, these data indicate that CAFG accelerates the bone-healing process after injury of long bones.

To specifically know the molecular target of CAFG, we next characterized the cellular signaling events being activated by CAFG. CAFG triggers BMP2-canonicalWnt/ $\beta$-catenin signaling in osteoblasts that resulted in the stimulation of osteoblast differentiation and mineralization. Although BMP2 signaling component is distinct from the known $\mathrm{Wnt} / \beta$-catenin signal transduction pathway, they may stimulate processes that cooperate with activated $\beta$-catenin to promote osteoblast differentiation. ${ }^{24,35}$ The ultimate outcome of the Wnt activation after treatment with CAFG resulted in the following sequence of events: increase of $\beta$-catenin nuclear translocation, and as Wnt activation is highly dependent on essential osteogenic transcription factor Runx2, we found activation of Runx2 promoter. The effect of CAFG was blocked by Dkk1, a blocker of $\mathrm{Wnt} / \beta$-catenin receptor and $\mathrm{FH} 535$ inhibitor of $\beta$-cateninTCF /LEF complex. Inhibition of $\beta$-catenin-TCF/LEF complex almost inhibited CAFG-induced BMP2 expression suggesting interdependence of the two signaling pathways. The effect of CAFG on signaling, function and gene expression of osteoblasts leading to possible anabolic action and antiosteoclastogenic effect is shown in Figure 8. The end result of this orchestrated activity improved BMD and biomechanical properties.

Impetus to this data, we can conclude that CAFG has ability to impart osteogenic effect at much lower dose through BMP2canonical/Wnt $/ \beta$-catenin signaling. The human equivalent dose of CAFG translates into $\sim 0.081 \mathrm{mg} / \mathrm{kg} / \mathrm{day}$ body weight. Therefore, for a 60-kg person, the daily requirement for CAFG is calculated to be $\sim 4.8 \mathrm{mg}$, which is easily achievable. Moreover, CAFG devoid of uterine estrogenicity and has pronounced effect on fracture healing. Therefore, its positioning as fracture healing and anti-osteoporotic agent is alluring.

\begin{abstract}
Materials and Methods
Reagents and chemicals. Cell culture media and supplements were purchased from Sigma-Aldrich (St. Louis, MO, USA). Human PTH (1-34) was purchased from Calbiochem (Pacific Center Ct, San Diego, CA, USA) and ALN was purchased from Sigma. All fine chemicals and inhibitors (SB203580, and Noggin) were purchased from Sigma-Aldrich. Dkk1 Recombinant exogenous protein was purchased from R\&D systems (Minneapolis, MN, USA), FH535 (2,5-Dichloro- $N$-(2-methyl-4-nitrophenyl)benzenesulfonamide) was purchased from Tocris Bioscience (Moorend Farm Avenue, Bristol, UK) and p38 MAP Kinase ELISA kit was purchased from Cell Signaling Technologies (Danvers, MA, USA). BMP2 ELISA was purchased from R\&D systems. ECL kit was purchased from GE Healthcare Bio-Sciences (Pittsburgh, PA, USA). Antibody was purchased from Abcam (Cambridge Science Park, Cambridge, UK). ${ }^{36,37}$
\end{abstract}

Mice calvarial cell culture. For each experiment, 1- to 2-day-old mice calvarial cells were used to harvest 10-20 calvarias at room temperature. Briefly, individual calvaria was surgically isolated from the skull, sutures were segregated

Figure 5 CAFG promotes osteoblast differentiation through BMP2 signaling pathway. (a) CAFG (10 nM) treatment in mice calvarial osteoblast cells exerts anti-apoptotic effects in osteoblast. Using Becton Dickinson FACS and FL-H channel (Annexin-V) and FL2-H channel (PI) CAFG treatment inhibited apoptosis of osteoblast cells. Shown in the figure are representative dot plots. (b) Quantification of flow cytometry data is shown as a percent of total cells. Values represent mean $\pm S$.E. ${ }^{*} P<0.05$ compared with control for early apoptosis. (c) ALP activity of CAFG after giving treatment with SB203580 inhibitor $(10 \mu \mathrm{M})$. Data represent mean $\pm \mathrm{S}$.E. ${ }^{*} P<0.05,{ }^{\star \star} P<0.01 \mathrm{compared}$ with

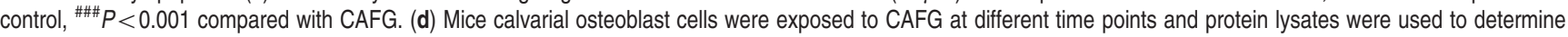
endogenous phospho-p38 MAPK activity after taking OD at $405 \mathrm{~nm}$. Data represent mean $\pm \mathrm{S}$.E. ${ }^{* *} P<0.001$ compared with control. (e) Western blot analysis of phoshorylated and unphosphorylated $P$-38 levels after $24 \mathrm{~h}$ treatment. (f) Western blot analysis of osteogenic gene BMP2 after giving CAFG treatment at different time points. (g) Relative mRNA expression of BMP2 after exogenous treatment with BMP2 (100 ng/ml) and BMP2 inhibitor noggin (50 ng/ml) at $24 \mathrm{~h}$ in mice calvarial osteoblast cells. (h) Western blot analysis after pretreatment of giving noggin treatment to mice calvarial osteoblast cells and then treatment of CAFG at $24 \mathrm{~h}$. Data normalized by constitutive expressing gene $\beta$-actin. (i) Secreted BMP2 levels were assessed in conditioned media after treatment with CAFG by ELISA. Data represent mean \pm S.E. from three independent experiments. ${ }^{*} P<0.05,{ }^{* * *} P<0.001$ compared with control. (j) Relative mRNA expression of Smad1 and ALP after CAFG exogenous BMP2 (100ng/ml) and noggin $(50 \mathrm{ng} / \mathrm{ml})$ treatment at $24 \mathrm{~h}$. (k) Activation effects of CAFG on BMP2 signaling pathway were tested using reporter construct $P$-Runx2-Luc. A full-length mouse Runx2 promoter construct was used to test this effect. Cells were transfected with construct for $24 \mathrm{~h}$ and treated with CAFG. Cell lysates were collected and luciferase activity was measured after $24 \mathrm{~h}$. Normalized control Renilla was used and plotted as fold activity over untreated control. Data represent mean \pm S.E. from three independent experiments; ${ }^{* *} P<0.001$ compared with control. (I) Western blot analysis of various osteogenic genes phospho-Smad1, Smad1, Smad4, Runx2 after $24 \mathrm{~h}$ treatment in mice calvarial osteoblast cells. Data normalized by internal control $\beta$-actin. (m) Relative mRNA expression of BMP2 after pretreatment with CAFG and SB inhibitor (10 $\mu \mathrm{M})$. Data represent mean \pm S.E. from three independent experiments. ${ }^{\star} P<0.05,{ }^{\star \star} P<0.01$ compared with control 

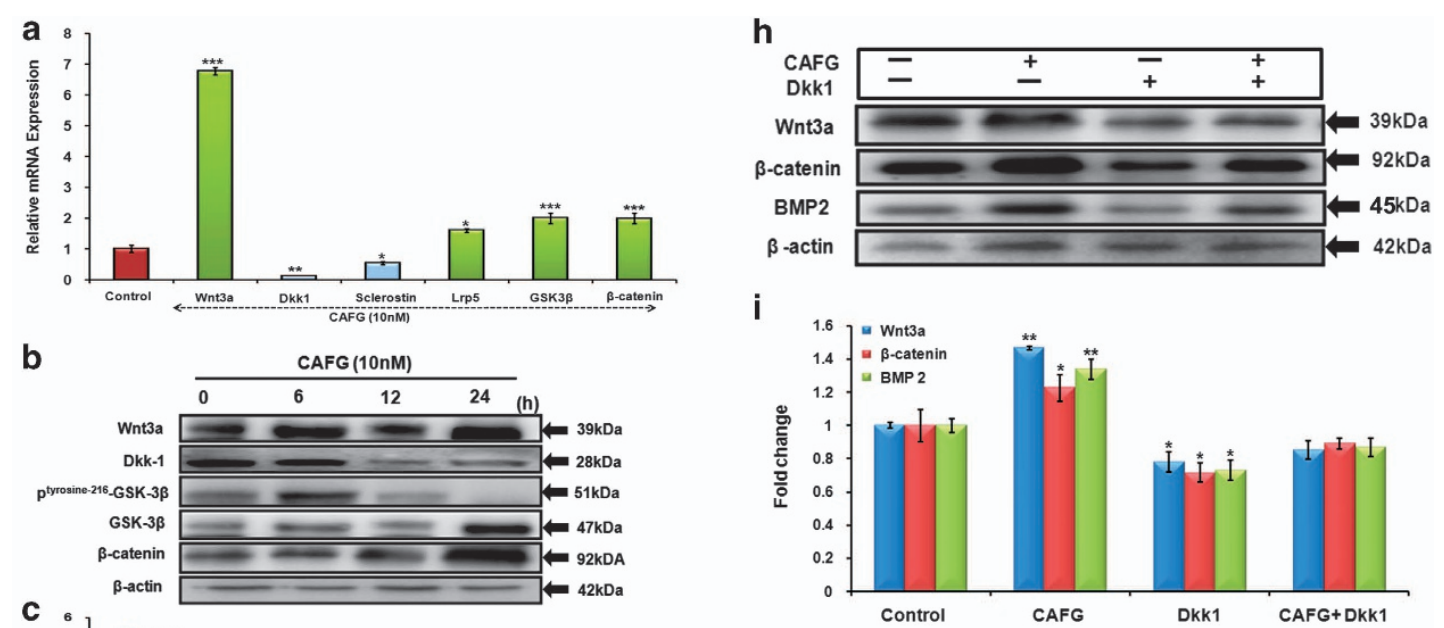

i
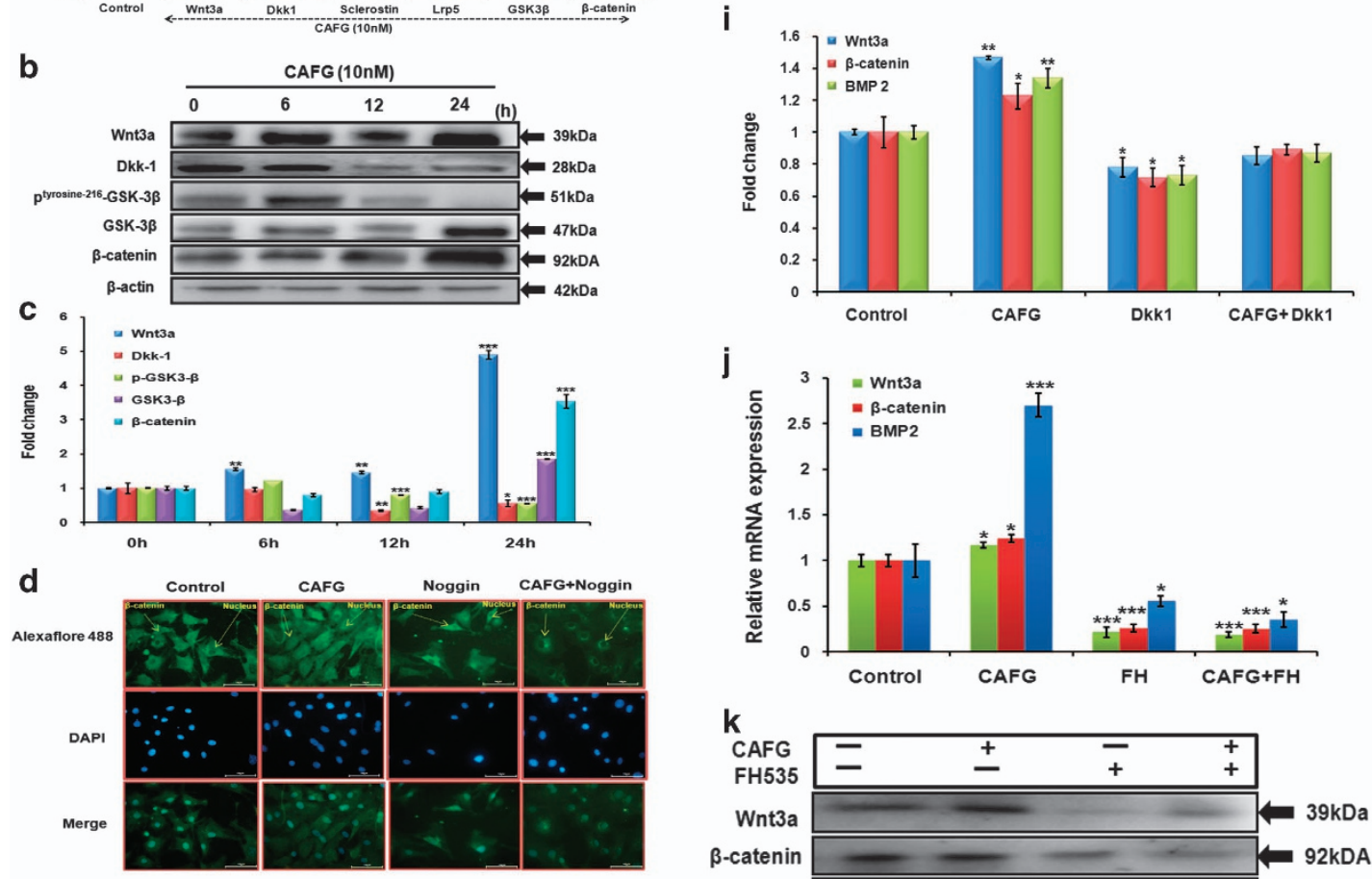

e
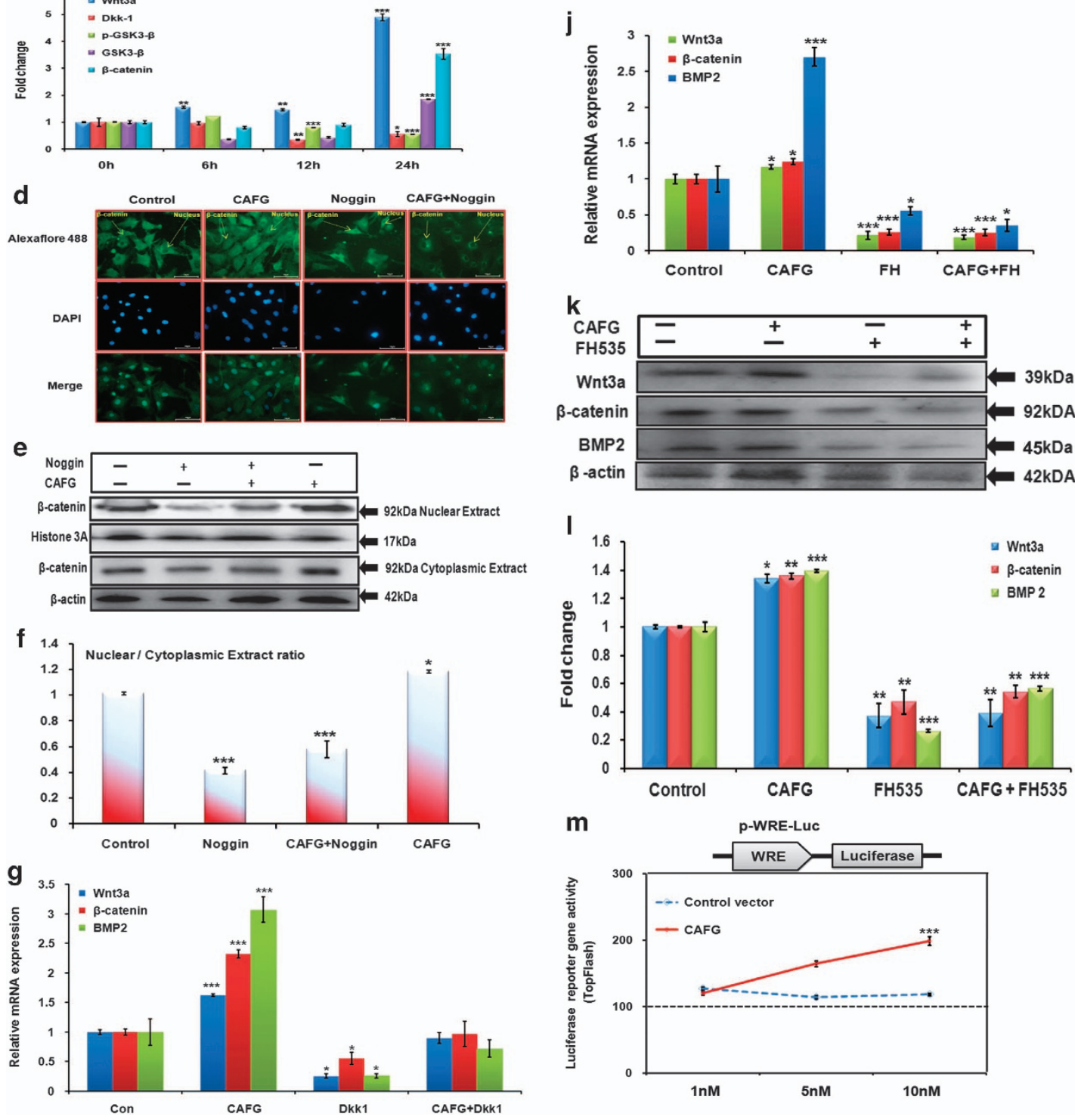
and adherent tissue material was cleaned by gentle scrapping. As described previously, ${ }^{36}$ the pooled calvarias were kept for repeated digestion $(15 \mathrm{~min} /$ digestion) with $0.05 \%$ trypsin and $0.1 \%$ collagenase $P$ to release cells. First digestion was discarded and cell was collected from next four digestions. Cells were cultured in a modified essential medium ( $\alpha$-MEM) containing $10 \%$ fetal calf serum (FCS) and 1\% penicillin/streptomycin (complete growth medium). MCOs were allowed to reach $70-80 \%$ confluence for the experiments.

Animal. All animal care and experimental procedures were approved by the Institutional Animal Ethics Committee. Female balb/c mice $(18 \pm 5 \mathrm{~g})$ were obtained from the National Laboratory Animal Centre. Animals were kept in a 12-h light-dark cycle, with controlled temperature $\left(22-24^{\circ} \mathrm{C}\right)$ and humidity $(50-60 \%)$ and free access to standard rodent food and water. ${ }^{36}$

Cell proliferation assay. We assayed cell proliferation by using BrdU incorporation assay. BMCs of treated groups were seeded on 96 well plates to differentiate towards osteogenic lineage. After differentiation, cells were kept for $24 \mathrm{~h}$ to arrest growth with serum-free media. BrdU $(10 \mathrm{ng} / \mathrm{ml})$ was added to the media. Then the cells were incubated for $4 \mathrm{~h}$. The cells were washed, fixated and then stained with the BrdU antibody by using a BrdU staining kit (Roche Applied Sciences, Branford, CT, USA) following the manufacturer's instruction. O.D. (Optical Density) has measured at $450 \mathrm{nM}^{36}$

Alkaline phosphatase activity (ALP) and mineralization assay of BMCs. At the end of the different treatments, mice were killed and BMCs from the femora were flushed out in osteoblast differentiation medium containing $10^{-7} \mathrm{M}$ dexamethasone (bone marrow differentiation medium). Cells were seeded $\left(2 \times 10^{6}\right.$ cells . per well) onto 12-well plates in bone marrow differentiation medium. BMCs were cultured for 21 days with a change of medium every $48 \mathrm{~h}$. At the end of the experiment, ALP activity was measured at $405 \mathrm{~nm}$ and mineralized nodules were stained and quantified at $405 \mathrm{~nm}$, as described for the mice calvarial osteoblast cells. ${ }^{36}$

q-PCR. SYBR green chemistry was for quantitative determination of various genes following an optimized protocol described before. The design of sense and antisense oligonucleotide primers was based on published cDNA sequences using the Universal ProbeLibrary (Roche Applied Sciences). Primer sequences are listed in Table 1. cDNA was synthesized with the RevertAid cDNA synthesis kit (Fermentas, Austin, TX, USA) using $2 \mu \mathrm{g}$ total RNA in $20 \mathrm{ml}$ reaction volume. For $\mathrm{Q}-\mathrm{PCR}$, the cDNA was amplified using Light Cycler 480 (Roche Molecular Biochemicals, Indianapolis, IA, USA). ${ }^{36}$

Oral bioavailability studies in Balb/c mice. Adult female Balb/c mice were used for this study. The animals were given a $1 \mathrm{mg} / \mathrm{kg}$ bolus dose of CAFG by oral gavage and killed at $0,15 \mathrm{~min}, 30 \mathrm{~min}, 1 \mathrm{~h}, 2 \mathrm{~h}, 3 \mathrm{~h}, 4 \mathrm{~h}, 6 \mathrm{~h}, 8 \mathrm{~h}, 12 \mathrm{~h}$ and $24 \mathrm{~h}$ after treatment. Three animals were taken at each time point. Plasma was collected for the determination of CAFG levels. Data that represent the concentration-drug profile at $\mathrm{Oh}$ time point were obtained from animals without any prior treatment. Sample processing was performed as described in previous study. ${ }^{36}$

Studies on the in vivo expression of CAFG responsive genes. Ten 1- to 2-day-old mice were divided into three equal groups and given a subcutaneous injection of either CAFG $(1 \mathrm{mg} / \mathrm{kg} /$ day and $5 \mathrm{mg} / \mathrm{kg} /$ day dose in $50 \mathrm{ml}$ ) or equal volume of vehicle (normal saline) for 3 consecutive days. At the end of the treatment, pups were euthanized, and individual calvaria were harvested and cleaned of adherent tissue materials by gentle scrapping. Total RNA was isolated, and Q-PCR for ALP, Runx2 and COL1 was performed as described earlier.

3D trabecular and cortical micro-architecture analysis by $\boldsymbol{\mu}$-CT. Sky Scan 1076 microCT scanner (Sky Scan, Aartselaar, Belgium) was used to carry out $\mu$-CT scanning of excised bones as described before. The bone samples were scanned at a resolution of $9 \mu \mathrm{m}$ and reconstruction was done using the Sky Scan Nrecon software. The X-ray source was set at $50 \mathrm{kV}$ and $200 \mathrm{~mA}$, with a pixel size of $9 \mu \mathrm{m}$. A hundred projections were acquired over an angle arrange of $180^{\circ} \mathrm{C}$. CTanalyser (CTAn, Skyscan) software was used to draw ellipsoid contours in selected trabecular bone. Mean intercept length method was used to calculate trabecular bone volume, Tb.N and Tb.Sp. of the distal femoral epiphysis (covering secondary spongiosa and the secondary ossification center), proximal tibial and lumber 5 vertebrae. Tb.Th and SMI were calculated according to the method of Hildebrand and Ruegsegger. 3D parameters were based on analysis of a Marching cubes-type model with a rendered surface. CTVol software was used to create $3 \mathrm{D}$ model of the bones. ${ }^{36}$

Fluorochrome labeling and bone histomorphometry. Crosssections ( $50 \mu \mathrm{m}$ thickness) of periosteal regions of undecalcified diaphysis tibial bone of each mouse were obtained using an Isomet-Slow Speed Bone Cutter (Buehler, Lake Bluff, IL, USA). Images were captured using Leica-Qwin software (Leica Microsystems Inc., Buffalo Grove, IL, USA) and bone forming rate/bone surface (BFR/BS) and MAR were calculated. Tetracycline was injected $30(20 \mathrm{mg} / \mathrm{kg})$ days before termination of treatment, whereas calcien $(20 \mathrm{mg} / \mathrm{kg}) 24 \mathrm{~h}$ before termination of treatment. ${ }^{36}$ For TRAP histochemistry, femur bones were fixed in $4 \%$ formaldehyde and decalcified using EDTA solution. The bones were dehydrated, sectioned in $5 \mu \mathrm{m}$ thick size, deparaffined and TRAP staining was performed according to previously published protocol. Histological section of bone stained for TRAP activity was analyzed with bioquant software. Analysis of osteoclast number and osteoclast surface was performed according to standardized protocols of the American Society for Bone and Mineral. ${ }^{38}$

Bone mechanical strength. Bone mechanical strength was examined by compression test of lumber 5 vertebrae $(\mathrm{L} 5)$ and breaking strength of femur with bone strength tester model TK 252C (Muromachi Kikai Co. Ltd., Tokyo, Japan), according to our previously published protocols. ${ }^{36}$

Figure 6 Effect of CAFG on Wnt signaling. (a) Relative mRNA expression of Wnt signaling genes after $24 \mathrm{~h}$ treatment on mice calvarial osteoblast cells with CAFG. Data represent mean \pm S.E. ${ }^{*} P<0.05$, ${ }^{\star *} P<0.01,{ }^{* * *} P<0.001$ compared with control. (b) Western blot analysis of Wnt3a, Dkk1, Sclerostin, Phospho-GSK3 $\beta$, GSK3 $\beta$ and $\beta$-catenin after $24 \mathrm{~h}$. Data normalized with internal control $\beta$-actin. (c) Quantitative assessment of proteins by densitometry. Data represent mean $\pm S$.E. ${ }^{\star} P<0.05,{ }^{* \star} P<0.01,{ }^{* \star *} P<0.001$ compared with $0 \mathrm{~h}$. (d) CAFG promotes $\beta$-catenin translocation after CAFG treatment in mice calvarial osteoblast cells at $24 \mathrm{~h}$ but translocation is inhibited by inhibitor noggin $(50 \mathrm{ng} / \mathrm{ml})$. Representative photomicrograph of subcellular localization of $\beta$-catenin was determined by immunofluorescence (magnification $\times 40$ ) under control and treatment conditions from three independent experiments $(n=3)$. (e) Nuclear and cytoplasmic extracts were prepared and $\beta$-catenin protein levels were detected by immune-blotting. Histone $3 \mathrm{~A}$ was used as loading control for nuclear extract and $\beta$-actin was used as loading controls for cytoplasmic fraction. (f) This figure shows densitometry analysis of $\beta$-catenin levels from three independent blots. Values represent mean \pm S.E. of three independent experiments $(n=3)$. ${ }^{\star} P<0.05,{ }^{* * *} P<0.001$ compared with control. (g) Relative mRNA expression Wnt3a, $\beta$-catenin and BMP2 after giving CAFG (10 nM) and exogenous recombinant Dkk1 $(100 \mathrm{ng} / \mathrm{ml})$ for $24 \mathrm{~h}$. Values are normalized with internal control GAPDH. ${ }^{*} P<0.05,{ }^{* \star \star} P<0.001$ compared with control. (h) Western blot analysis of above genes in the presence of CAFG and Dkk1. Internal control is $\beta$-actin. (i) Quantitative analysis of the proteins by densitometry. Values represent mean $\pm S$.E. of three independent experiments. ${ }^{*} P<0.05,{ }^{* * *} P<0.001$ compared with control. (j) Relative mRNA expression of Wnt3a, $\beta$-catenin and BMP2 after giving CAFG (10 nM) and FH535 (20 $\left.\mu \mathrm{M}\right)$ for $24 \mathrm{~h}$.Values are normalized with internal control GAPDH. ${ }^{*} P<0.05,{ }^{* \star *} P<0.001$ compared with control. (k) Western blot analysis of above genes in the presence of CAFG and FH535. Internal control is $\beta$-actin. (I) Densitometry analysis of above expressing protein. Values represent mean $\pm S$.E. of three independent experiments. ${ }^{*} P<0.05$, ${ }^{* *} P<0.01,{ }^{* \star \star} P<0.001$ compared with control. (m) TOP FLASH activity of TCF/LEF in the presence of CAFG (10 nM) compared with control. $P$-WRE-Luc contained luciferase (Luc) enzyme tagged downstream of the TCF-binding element in responding to Wnt/ $\beta$-catenin signaling. For the detection of Wnt transcriptional activity, luciferase reporter-gene analysis was performed in HEK-293 cells, osteoblast cells transfected with plasmid and cell lysates were collected for TOP Flash plasmid activity. Luciferase and $\beta$-galactosidase activities were measured $48 \mathrm{~h}$ after transfection according to standard methods and were used to control transfection efficiency, CAFG (10nM) was applied for 24h. Data represent mean \pm S.E. ${ }^{* * \star} P<0.001$ compared with control 
a
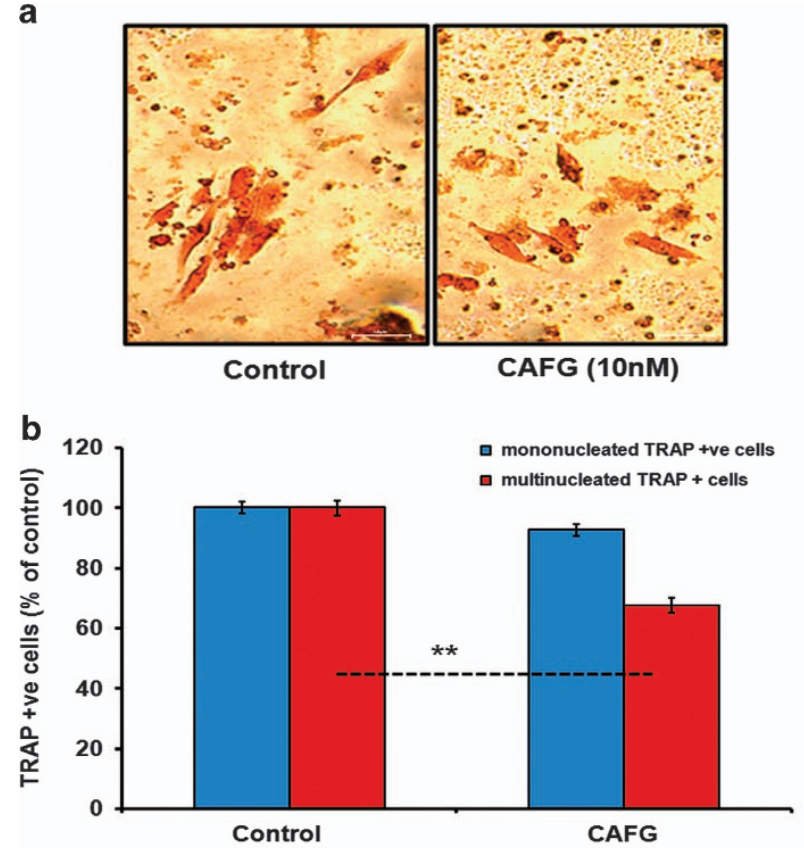

c

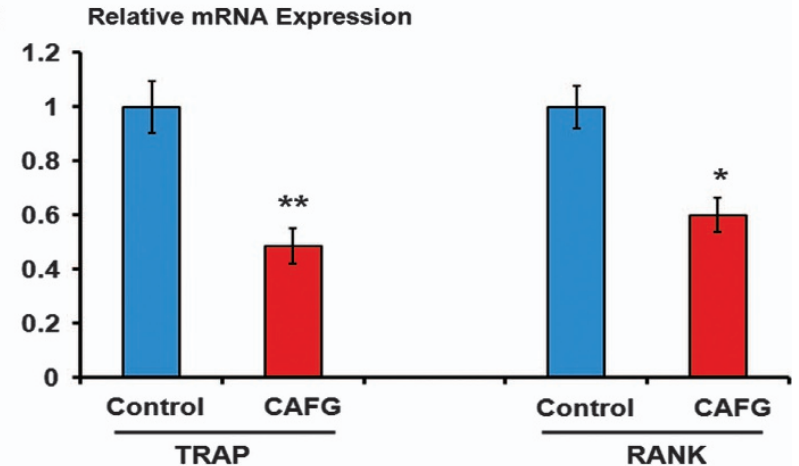

d

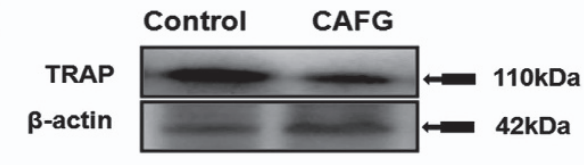

e

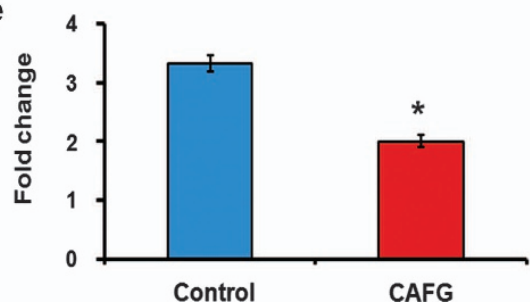

Figure 7 Effect of CAFG on osteoclast. (a) Representative photomicrograph $(\times 40)$ shows that $C A F G$ at $10 \mathrm{nM}$ concentrations inhibits osteoclastogenesis from BMCs in the presence of M-CSF $(10 \mathrm{ng} / \mathrm{ml})$ and RANKL $(50 \mathrm{ng} / \mathrm{ml})$ in 5-day culture. (b) Quantitative representation of $\mathrm{TRAP}^{+}$multinuclear and mononuclear cells after CAFG treatment. (c) Relative mRNA expression of TRAP and RANK determined by Q-PCR from the total RNA isolated from differentiated osteoclast normalized with GAPDH. (d) Western blot of TRAP and (e) densitometry analysis of expressing TRAP protein normalized with loading control $\beta$-actin. Values represent mean \pm S.E. of three independent experiments. ${ }^{*} P<0.05$ compared with control
Uterine histology and histomorphometry. The uterus of mice was weighed and fixed in $4 \%$ paraformaldehyde and dehydrated in ascending grades of isopropanol, cleared in xylene and embedded in paraffin wax using standard procedures. Transverse sections $(5 \mu \mathrm{m})$ were stained with hematoxylin and eosin and representative images were captured. Total uterine area, luminal area and luminal epithelial height were measured using Leica Qwin-Semiautomatic Image Analysis software (Leica). ${ }^{36}$

Bone biochemical marker analysis. Rat-MID OCN EIA (Immunodiagnostic Systems Limited, Boldon, UK) was performed using serum from treated and vehicle groups using manufacturer's protocol. ${ }^{36}$

Osteoclast culture and TRAP Staining. In vitro osteoclastogenesis was carried out using a standard protocol. ${ }^{18,26,38}$ Mouse BMCs were flushed from femur bone using $\alpha$-minimum essential medium eagle $(\alpha-M E M)$. Cells were seeded in $\mathrm{T}_{25}$ flask for overnight in osteoclast medium ( $\alpha$-MEM, 10\% FCS, antibiotic, Earle's balanced salt solution, $10 \mathrm{ng} / \mathrm{ml}$ MCSF). After overnight incubation, non-adherent BMCs were seeded in 48-well plates at a density of 200000 cells/well and cultured for $5-6$ days in $\alpha$-MEM containing 10\% FCS, Earle's balanced salt solution, $50 \mathrm{ng} / \mathrm{ml}$ RANKL and $10 \mathrm{ng} / \mathrm{ml}$ MCSF and CAFG at $10 \mathrm{nM}$ concentrations. Medium was replaced after every $48 \mathrm{~h}$, after 6 days of culture. Cells were washed with PBS and then fixed in $4 \%$ paraformaldehyde for staining and for RNA extraction using TRIZOL for analysis of TRAP and RANK mRNA levels by real-time PCR. Fixed cells were followed by TRAP staining using the standardized protocol. ${ }^{38,26}$

Cell viability assay of CAFG. The cytotoxicity of CAFG on bone marrow osteoblast and chondrocytes was examined by MTT assay. Treated groups were differentiated into osteoblast cells and assess the cell proliferation and viability. Articular chondrocytes of newborn mice pups (1- to 2-day old) were treated with different concentrations of CAFG for 2 and 4 days. The cell viability/cytotoxicity was determined by using MTT assay (OD at $570 \mathrm{~nm})$.

Alcian blue staining. Mice articular chondrocyte cells are in pre-chondrocyte cells proliferative stage. At day 7 (columnar chondrocyte cells-highly proliferative stage) and day 14 (hypertrophic chondrocyte stage), chondrocytes culture cells were fixed with $4 \%$ paraformaldehyde for $15 \mathrm{~min}$ at room temperature and then incubated overnight with $0.1 \%$ alcian blue $(\mathrm{pH} 1-2)$. Excess stain was washed off with $3 \%$ glacial acetic acid with and pictures were taken. For quantitative analysis, bound alcian blue dye was extracted with $200 \mathrm{ml}$ of $6 \mathrm{M}$ guanidine $\mathrm{HCl}$ overnight at room temperature. The optical density of the extracted dye was measured at a wavelength of $630 \mathrm{~nm}^{39}$

Apoptosis assay. Mice calvarial osteoblast cells were cultured in $50-60 \%$ confluence by serum withdrawal for $3 \mathrm{~h}$ and treated with CAFG $(10 \mathrm{nM})$ or without treatment for $24 \mathrm{~h}$ in $\alpha$-MEM containing $0.5 \%$ FBS Annexin-V/PI staining for FACS analysis was carried out using Calbiochem Annexin-V-FITC Apoptosis Detection Kit (Calbiochem) according to the manufacturer's instructions. ${ }^{36}$

Western blot analysis. Mice calvarial osteoblast cells were grown to $80 \%$ confluency followed by exposure to compounds (CAFG) for different time periods. Cells were washed with cold phosphate-buffered saline (vehicle), and whole-cell lysates were prepared by the addition of lysis buffer Sigma-Aldrich containing a protease inhibitor mixture Sigma-Aldrich. $30-50 \mu \mathrm{g}$ of protein was loaded per lane and separated on a $10 \%$ polyacrylamide gel, followed by transfer to a PVDF membrane (Millipore, Billerica, MA, USA) by electroblotting. Membrane was blocked for nonspecific binding in $5 \%$ nonfat dry milk and followed by incubation with an primary antibody (Abcam) at $4{ }^{\circ} \mathrm{C}$ overnight. Membranes were washed and probed with a horseradish peroxidase-conjugated secondary antibody (Abcam) and visualized by an enhanced chemi-luminescence system (GE Healthcare Life Sciences, Lucknow, India) according to the manufacturer's instructions. ${ }^{36}$

BMP2 ELISA. For the quantitative determination of BMP2 concentration in cell culture supernates, osteoblast cells were seeded $\left(20 \times 10^{3}\right.$ cells/well) in six-well plates. It contains $\mathrm{CHO}$ cell expressed recombinant human BMP2. Cell supernates were exposed to CAFG, Noggin and CAFG + Noggin and OD measured at $405 \mathrm{~nm} .{ }^{37}$

P-38 MAPK ELISA. For measuring total and phospho-p38 MAPK, osteoblast $\left(20 \times 10^{3}\right.$ cells/well) were seeded in six-well plates. Cells were exposed to CAFG 


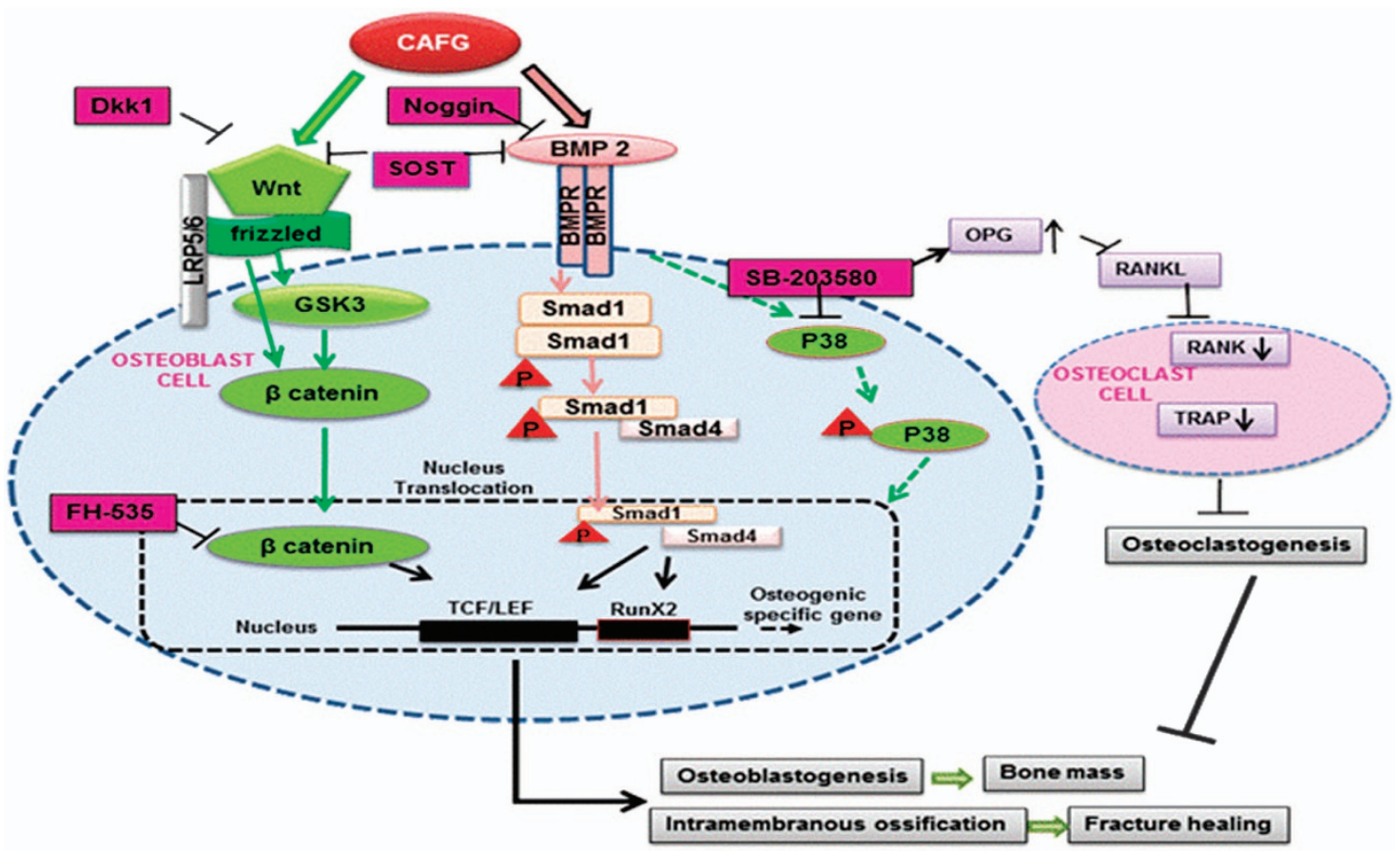

Figure 8 Schematic diagram outlining the novel molecular targets of CAFG leading to bone anabolic effects in osteogenic cells and fracture healing induced by BMP2/ Wnt $\beta$-catenin pathway. CAFG directly bind to BMP receptor and initiates Smad-dependent signaling. After phosphorylation of Smad1, Smad4 directly binds to phosphoSmad1 and translocates to the nucleolus where they initiate transcription factor RunX2. Besides this CAFG binds to Wnt-frizzled receptor and activates $\beta$-catenin translocation to the nucleolus where it binds to TCF/LEF complex and promotes osteoblastogenesis. CAFG increases OPG levels to inhibit osteoclastogenesis. The same pathway further initiates intramembranous ossification at the site of injury to repair bone

for different time intervals $(0,6,12,24 \mathrm{~h})$. Cells were lysed and proteins were quantified by Bradford kit (Cell Signaling Technologies) following the manufacturer's instruction. And OD measured at $405 \mathrm{~nm}^{37}$

Nuclear and cytosolic protein extraction experiment. Mice primary osteoblast cells were incubated in medium with CAFG, Noggin and CAFG + Noggin for $24 \mathrm{~h}$. Nuclear and cytosolic protein were extracted by different lysis buffer using the manufacturer's protocol (Cellytic NuCLEAR Extraction Kit, SigmaAldrich). These extracted proteins were immunoblotted with $\beta$-catenin (Abcam) for nuclear translocation. ${ }^{36}$

Immunocytochemistry. Mice primary osteoblast cells were incubated in medium with CAFG, Noggin and CAFG + Noggin and were grown on Lab-Tek Chamber Slides (Nunc, Penfield, NY, USA) for $24 \mathrm{~h}$. For immunocytochemistry, cells were fixed with $4 \%$ formaldehyde followed by permeabilization with $0.1 \%$ Triton X-100 and incubation in primary antibody ( $\beta$-catenin) for overnight. Alexa Flour-488 (Invitrogen, Carlsbad, CA, USA) used as secondary antibody. Fluorescence was captured $(\times 40)$ using fluorescent microscope (Eclipse 80i, Nikon, Tokyo, Japan), with the aid of appropriate filter (Excitation $495 \mathrm{~nm}$ and Emission $519 \mathrm{~nm}){ }^{36}$

Luciferase reporter analysis. Runx2 luciferase vector and renilla were purchase from GeneCopoeia (Rockville, MD, USA). Primary mice calvarial osteoblast cells were plated onto 24 -well plates. At $60-70 \%$ confluency, cells were transfected with Runx2 luciferase and renilla vector with $700 \mathrm{ng}$. After $24 \mathrm{~h}$ of post-transfection, cells were treated with or without CAFG in differentiating media. Lysates were then collected and luciferase intensity was determined using Dual assay luciferase kit (Promega Corporation, Madison, WI, USA). ${ }^{40}$

TOPflash (TCF/LEF reporter plasmid). For the detection of Wnt transcriptional activity, luciferase reporter-gene analysis was performed in HEK-293 cells with CAFG at the indicated concentrations. The cells were transfected with $1 \mathrm{mg}$ TOP Flash or FOP Flash plasmid (Upstate Biotechnology, Lake Placid, NY, USA), $1 \mathrm{mg} \beta$-galactosidase vector (Promega, Madison, WI, USA) using Lipofectamine 2000 (Invitrogen). Luciferase and $\beta$-galactosidase activities were measured $48 \mathrm{~h}$ after transfection according to standard methods and were used to control transfection efficiency. ${ }^{40}$

\section{Conflict of Interest}

The authors declare no conflict of interest.

Acknowledgements. Grant from CSIR (BSC0201), ASTHI and Department of Biotechnology (DBT), Government of India are acknowledged. Scientist and In charge of Electron Microscopy for confocal imaging. The CDRI communication number is $184 / 2014 / R T$.

\section{Authors contributions}

Study conception and design: P Kushwaha, V Khedgikar, J Gautam, D Singh, R Maurya, D Prasad Mishra, N Chattopadhyay, PR Mishra, R Trivedi. Acquisition of data: P Kushwaha, V Khedgikar, J Gautam, PR Mishra, R Trivedi. Analysis and interpretation of data: P Kushwaha, V Khedgikar, J Gautam, P Dixit, R Chillara, A Verma, R Thakur, D Singh, R Maurya, D Prasad Mishra, N Chattopadhyay, PR Mishra, R Trivedi. Drafting of manuscript: P Kushwaha, V Khedgikar, J Gautam, PR Mishra, R Trivedi. Critical revision: P Kushwaha, V Khedgikar, J Gautam, D Singh, R Maurya, D Prasad Mishra, N Chattopadhyay, PR Mishra, R Trivedi.

1. Manolagas SC. Birth and death of bone cells: basic regulatory mechanisms and implications for the pathogenesis and treatment of osteoporosis. Endocr Rev 2000; 21: 115-137.

2. Orwoll ES, Klein RF. Osteoporosis in men. Endocr Rev 1995; 16: 87-116.

3. Hodsman AB, Bauer DC, Dempster DW, Dian L, Hanley DA, Harris ST et al. Parathyroid hormone and teriparatide for the treatment of osteoporosis: a review of the evidence and suggested guidelines for its use. Endocr Rev 2005; 26: 688-703.

4. Stepan JJ, Alenfeld F, Boivin G, Feyen JH, Lakatos P. Mechanisms of action of antiresorptive therapies of postmenopausal osteoporosis. Endocr Regul 2003; 37: 225-238.

5. Wardlaw SL. Citation for the Distinguished Physician Award of the Endocrine Society to Dr. John P. Bilezikian. Endocr Rev 1998; 19: 516-517. 
6. Cipriano CA, Issack PS, Shindle L, Werner CM, Helfet DL, Lane JM. Recent advances toward the clinical application of PTH (1-34) in fracture healing. Hss J 2009; 5: 149-153.

7. Cosman F. The prevention and treatment of osteoporosis: a review. MedGenMed 2005; 7: 73.

8. Ivergard M, Strom O, Borgstrom F, Burge RT, Tosteson AN, Kanis J. Identifying cost-effective treatment with raloxifene in postmenopausal women using risk algorithms for fractures and invasive breast cancer. Bone 2010; 47: 966-974.

9. Jordan VC, Gapstur S, Morrow M. Selective estrogen receptor modulation and reduction in risk of breast cancer, osteoporosis, and coronary heart disease. J Natl Cancer Inst 2001; 93: 1449-1457.

10. Chou MY, Yan D, Jafarov T, Everett ET. Modulation of murine bone marrow-derived CFU-F and CFU-OB by in vivo bisphosphonate and fluoride treatments. Orthod Craniofac Res 2009; 12: 141-147.

11. Black DM, Greenspan SL, Ensrud KE, Palermo L, McGowan JA, Lang TF et al. The effects of parathyroid hormone and alendronate alone or in combination in postmenopausal osteoporosis. N Engl J Med 2003; 349: 1207-1215.

12. Finkelstein JS, Hayes A, Hunzelman JL, Wyland JJ, Lee H, Neer RM. The effects of parathyroid hormone, alendronate, or both in men with osteoporosis. N Engl J Med 2003; 349: 1216-1226.

13. Dixit $P$, Chillara R, Khedgikar V, Gautam J, Kushwaha P, Kumar A et al. Constituents of Dalbergia sissoo Roxb. leaves with osteogenic activity. Bioorg Med Chem Lett 2012; 22: 890-897.

14. Chandra P, Sachan N, Pal D. Protective effect of Dalbergia sissoo Roxb. ex DC. (family: Fabaceae) leaves against experimentally induced diarrhoea and peristalsis in mice. Toxicol Ind Health; e-pub ahead of print 20 June 2013.

15. Sashidhara KV, Kumar M, Khedgikar V, Kushwaha P, Modukuri RK, Kumar A et al. Discovery of coumarin-dihydropyridine hybrids as bone anabolic agents. J Med Chem 2013; 56: 109-122

16. Garnero $\mathrm{P}$, Sornay-Rendu $\mathrm{E}$, Chapuy MC, Delmas PD. Increased bone turnover in late postmenopausal women is a major determinant of osteoporosis. J Bone Miner Res 1996; 11: 337-349.

17. Khedgikar V, Gautam J, Kushwaha $P$, Kumar A, Nagar GK, Dixit $P$ et al. A standardized phytopreparation from an Indian medicinal plant (Dalbergia sissoo) has antiresorptive and bone-forming effects on a postmenopausal osteoporosis model of rat. Menopause 2012; 19: $1336-1346$.

18. Siddiqui JA, Swarnkar G, Sharan K, Chakravarti B, Sharma G, Rawat P et al. 8,8"-Biapigeninyl stimulates osteoblast functions and inhibits osteoclast and adipocyte functions: osteoprotective action of 8,8 "-biapigeninyl in ovariectomized mice. $\mathrm{Mol}$ Cell Endocrinol 2010; 323: 256-267.

19. Zhang L, Zhang X, Li KF, Li DX, Xiao YM, Fan YJ et al. Icariin promotes extracellular matrix synthesis and gene expression of chondrocytes in vitro. Phytother Res 2012; 26: 1385-1392.

20. Akiyama H, Chaboissier MC, Martin JF, Schedl A, de Crombrugghe B. The transcription factor Sox9 has essential roles in successive steps of the chondrocyte differentiation pathway and is required for expression of Sox5 and Sox6. Genes Dev 2002; 16: 2813-2828.

21. Furumatsu T, Matsumoto-Ogawa E, Tanaka T, Lu Z, Ozaki T. ROCK inhibition enhances aggrecan deposition and suppresses matrix metalloproteinase-3 production in human articular chondrocytes. Connect Tissue Res 2013; 55: 89-95.

22. Wuelling M, Vortkamp A. Chondrocyte proliferation and differentiation. Endocr Dev 2011; 21: 1-11.

23. He YX, Zhang G, Pan XH, Liu Z, Zheng LZ, Chan CW et al. Impaired bone healing pattern in mice with ovariectomy-induced osteoporosis: A drill-hole defect model. Bone 2011; 48: 1388-1400.

24. Rawadi G, Vayssiere B, Dunn F, Baron R, Roman-Roman S. BMP-2 controls alkaline phosphatase expression and osteoblast mineralization by a Wnt autocrine loop. J Bone Miner Res 2003; 18: 1842-1853.

25. Glass DA 2nd, Bialek P, Ahn JD, Starbuck M, Patel MS, Clevers H et al. Canonical Wnt signaling in differentiated osteoblasts controls osteoclast differentiation. Dev Cell 2005; 8: 751-764.
26. Singh US, Shankar R, Kumar A, Trivedi R, Chattopadhyay N, Shakya N et al. Synthesis and biological evaluation of indolyl bisphosphonates as anti-bone resorptive and anti-leishmanial agents. Bioorg Med Chem 2008; 16: 8482-8491.

27. Tyagi AM, Gautam AK, Kumar A, Srivastava K, Bhargavan B, Trivedi R et al. Medicarpin inhibits osteoclastogenesis and has nonestrogenic bone conserving effect in ovariectomized mice. Mol Cell Endocrinol 2010; 325: 101-109.

28. Yamazaki M, Nakajima F, Ogasawara A, Moriya H, Majeska RJ, Einhorn TA. Spatial and temporal distribution of CD44 and osteopontin in fracture callus. J Bone Joint Surg Br 1999; 81: 508-515.

29. Knight MN, Hankenson KD. Mesenchymal stem cells in bone regeneration. Adv Wound Care (New Rochelle) 2013; 2: 306-316.

30. Secreto FJ, Hoeppner LH, Westendorf JJ. Wnt signaling during fracture repair. Curr Osteoporos Rep 2009; 7: 64-69.

31. Chen $\mathrm{Y}$, Whetstone HC, Lin AC, Nadesan $\mathrm{P}$, Wei Q, Poon R et al. Beta-catenin signaling plays a disparate role in different phases of fracture repair: implications for therapy to improve bone healing. PLoS Med 2013; 4: e249.

32. Mi M, Jin H, Wang B, Yukata K, Sheu TJ, Ke QH et al. Chondrocyte BMP2 signaling plays an essential role in bone fracture healing. Gene 2013; 512: 211-218.

33. Kloen $\mathrm{P}$, Di Paola M, Borens $\mathrm{O}$, Richmond J, Perino G, Helfet DL et al. BMP signaling components are expressed in human fracture callus. Bone 2003; 33: 362-371.

34. Tanaka K, Tanaka S, Sakai A, Ninomiya T, Arai Y, Nakamura T. Deficiency of vitamin A delays bone healing process in association with reduced BMP2 expression after drill-hole injury in mice. Bone 2010; 47: 1006-1012.

35. Bain G, Muller T, Wang X, Papkoff J. Activated beta-catenin induces osteoblast differentiation of $\mathrm{C} 3 \mathrm{H} 10 \mathrm{~T} 1 / 2$ cells and participates in BMP2 mediated signal transduction. Biochem Biophys Res Commun 2003; 301: 84-91.

36. Khedgikar V, Kushwaha P, Gautam J, Verma A, Changkija B, Kumar A et al. Withaferin A: a proteasomal inhibitor promotes healing after injury and exerts anabolic effect on osteoporotic bone. Cell Death Dis 2013; 4: e778.

37. Bhargavan B, Singh D, Gautam AK, Mishra JS, Kumar A, Goel A et al. Medicarpin, a legume phytoalexin, stimulates osteoblast differentiation and promotes peak bone mass achievement in rats: evidence for estrogen receptor beta-mediated osteogenic action of medicarpin. J Nutr Biochem 2012; 23: 27-38.

38. Khan K, Singh A, Mittal M, Sharan K, Singh N, Dixit P et al. [6]-Gingerol induces bone loss in ovary intact adult mice and augments osteoclast function via the transient receptor potential vanilloid 1 channel. Mol Nutr Food Res 2012; 56: 1860-1873.

39. Asahina I, Sampath TK, Nishimura I, Hauschka PV. Human osteogenic protein-1 induces both chondroblastic and osteoblastic differentiation of osteoprogenitor cells derived from newborn rat calvaria. J Cell Biol; 1993; 123: 921-933.

40. Guo AJ, Choi RC, Cheung AW, Chen VP, Xu SL, Dong TT et al. Baicalin, a flavone, induces the differentiation of cultured osteoblasts: an action via the Wnt/beta-catenin signaling pathway. J Biol Chem 2011; 286: 27882-27893.

(1) (-) $\Theta$ Cell Death and Disease is an open-access journal published by Nature Publishing Group. This work is licensed under a Creative Commons Attribution-NonCommercialNoDerivs 3.0 Unported License. The images or other third party material in this article are included in the article's Creative Commons license, unless indicated otherwise in the credit line; if the material is not included under the Creative Commons license, users will need to obtain permission from the license holder to reproduce the material. To view a copy of this license, visit http://creativecommons.org/licenses/ by-nc-nd/3.0/

Supplementary Information accompanies this paper on Cell Death and Disease website (http://www.nature.com/cddis) 